Associate Editor: Simon Kennedy

\title{
Plasma membrane calcium ATPases (PMCAs) as potential targets for the treatment of essential hypertension
}

\author{
Robert Little ${ }^{a}$, Elizabeth J. Cartwright ${ }^{a}$, Ludwig Neyses ${ }^{a}$, Clare Austin ${ }^{\mathrm{b}, *}$ \\ a The Institute of Cardiovascular Sciences, The University of Manchester, UK \\ ${ }^{\mathrm{b}}$ Faculty of Health and Social Care, Edge Hill University, UK
}

\section{A R T I C L E I N F O}

Available online 25 January 2016

\section{Keywords:}

Blood pressure

Hypertension

Plasma membrane calcium ATPase

Resistance artery

Atp2b1

Antihypertensive

\begin{abstract}
A B S T R A C T
The incidence of hypertension, the major modifiable risk factor for cardiovascular disease, is increasing. Thus, there is a pressing need for the development of new and more effective strategies to prevent and treat hypertension. Development of these relies on a continued evolution of our understanding of the mechanisms which control blood pressure (BP).

Resistance arteries are important in the regulation of total peripheral resistance and BP; changes in their structure and function are strongly associated with hypertension. Anti-hypertensives which both reduce BP and reverse changes in resistance arterial structure reduce cardiovascular risk more than therapies which reduce BP alone. Hence, identification of novel potential vascular targets which modify BP is important.

Hypertension is a multifactorial disorder which may include a genetic component. Genome wide association studies have identified ATP2B1, encoding the calcium pump plasma membrane calcium ATPase 1 (PMCA1), as having a strong association with BP and hypertension. Knockdown or reduced PMCA1 expression in mice has confirmed a physiological role for PMCA1 in BP and resistance arterial regulation. Altered expression or inhibition of PMCA4 has also been shown to modulate these parameters. The mechanisms whereby PMCA1 and 4 can modulate vascular function remain to be fully elucidated but may involve regulation of intracellular calcium homeostasis and/or comprise a structural role. However, clear physiological links between PMCA and BP, coupled with experimental studies directly linking PMCA1 and 4 to changes in BP and arterial function, suggest that they may be important targets for the development of new pharmacological modulators of BP.
\end{abstract}

(c) 2016 Elsevier Inc. All rights reserved.

\section{Contents}

\section{Introduction}

Hypertension is a major public health issue and is responsible for considerable morbidity and mortality. As such, there is a continued need for the identification of new targets for more effective treatments for high blood pressure (BP). Changes in the structure and function of resistance arteries play a key role in the development of hypertension (Heagerty et al., 2010; Rizzoni \& Agabiti-Rosei, 2012).

\footnotetext{
Abbreviations: AngII, angiotensin II; Atp2b1, gene for PMCA1 protein; BP, blood pressure; [ $\mathrm{Ca}^{2+}$ ], intracellular free calcium concentration; GWAS, genome-wide association study; NCX,

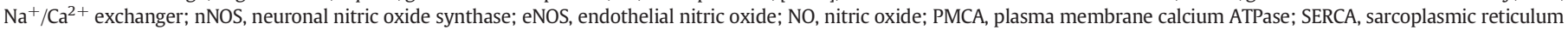
calcium ATPase; VSMC, vascular smooth muscle cell; VSMCs, vascular smooth muscle cells.

* Corresponding author at: Edge Hill University, St Helens Road, Ormskirk, Lancashire L39 4QP, UK.

E-mail address: Austincl@edgehill.ac.uk (C. Austin).
} 
Plasma membrane calcium ATPases (PMCAs) are ATP driven calmodulin-dependent pumps. PMCAs extrude $\mathrm{Ca}^{2+}$ ions from the cell and may thus contribute to the regulation of global, and sub-cellular, concentrations of intracellular free $\mathrm{Ca}^{2+}\left(\left[\mathrm{Ca}^{2+}\right]_{i}\right)$ (Karaki et al., 1997; Carafoli et al., 2001; Cartwright et al., 2011). However, it is now evident that PMCAs also have important roles as scaffold proteins whereby they may play a key role in signal transduction (Schuh et al., 2001; Williams et al., 2006; Cartwright et al., 2007; Strehler, 2015). Mammalian PMCAs belong to a multigene family of four different genes (ATP2B1-4 in humans) which encode respectively for PMCA proteins $1-4$. The protein expression of PMCA2 and 3 is limited, principally to neuronal-type cells, however, PMCA1 and 4 are expressed throughout the body (Carafoli, 1991; Keeton et al., 1993; Street et al., 1998; Okunade et al., 2004).

In this review we focus on essential (primary) hypertension and provide an overview of current knowledge relating to the regulatory effects of PMCAs on the resistance vasculature and effects on BP. Based on this we present an argument to support PMCA-mediated pathways as promising new targets for the treatment of hypertension. Whilst we recognise the importance of cardiac function in relation to BP control such a broad topic is beyond the scope of this review. PMCAs provide only a minor contribution to expulsion of total $\mathrm{Ca}^{2+}$ from cardiomyocytes (Bers, 2000). However, ongoing studies seek to clearly define the role of PMCAs in other cardiac cell types and under pathological conditions, and we direct interested readers to some of the publications in this area (Oceandy et al., 2007; Mackiewicz et al., 2009; Wu et al., 2009; Chen et al., 2010; Cartwright et al., 2011).

\section{Hypertension}

\subsection{A global clinical issue}

Hypertension is the major modifiable risk factor for cardiovascular disease, the most common cause of morbidity and mortality worldwide (Whelton, 1994; Wilson, 1994; Yusuf et al., 2001; Ezzati et al., 2002; WHO, 2013). Chronically elevated BP potentiates the risk of stroke, heart and renal failure and cardiac events (Whelton, 1994; Kearney et al., 2005). Since 2010 it has been estimated that hypertension contributes to more than 9.4 million deaths and 7\% of global DALYs (Disability-Adjusted Life Burden as a representation of the numbers of years lost due to ill health or early death) annually, and was the single greatest risk factor globally for these (Lim et al., 2012). It is estimated that 30$40 \%$ of the world's population suffers from hypertension, although the true incidence may be higher as elevated $\mathrm{BP}$ can remain asymptomatic (Lawes et al., 2008; Roger et al., 2012; Mancia et al., 2013). The prevalence of hypertension increases with ageing; whilst it has been estimated that fewer than $10 \%$ of people under the age of 40 may have elevated $\mathrm{BP}$, more than $60 \%$ of people aged over 70 require clinical intervention for hypertension (Lloyd-Jones et al., 2005; Egan et al., 2010). The world's population is ageing; the number of people over 60 years of age has doubled since 1980 and is predicted to reach 2 billion by 2050 (WHO, 2014). A consequence of this is an increased number of people living with hypertension and associated complications. Indeed, it has been estimated that between 1980 and 2008 the global number of people with hypertension rose from 600 million to almost 1 billion (Danaei et al., 2011), and that this number is continuing to rise (Fields et al., 2004; Heidenreich et al., 2011).

The relative risk for cardiovascular disease is directly associated with the absolute level of BP (Whitworth, 2003), with the risk of cardiovascular disease having been reported to double for each $20 / 10 \mathrm{mmHg}$ increment increase in BP (Chobanian et al., 2003). Treatments for hypertension often involve a combination of lifestyle changes and pharmacological intervention and, when successful, can have a highly positive impact on cardiovascular risk. Data from randomised controlled trials and prospective studies have shown that lowering BP by even 5 $6 \mathrm{~mm} \mathrm{Hg}$ is associated with approximately $20 \%$ and $40 \%$ reduction in adverse coronary events and stroke respectively (Lewington et al., 2002;
Law et al., 2009). However, some current therapeutic strategies appear to be of limited effectiveness for an increasing number of patients, with multidrug resistance or poor adherence to treatment regimes being reported (Morisky et al., 2008; Tomaszewski et al., 2014; Vega \& Bisognano, 2014; Vongpatanasin, 2014; Sakhuja et al., 2015). Resistant hypertension is associated with increased target organ damage and cardiovascular complications (Muiesan et al., 2013). As such, and alongside likely increasing demand from an increasingly ageing global population, there is a pressing need for development of new and more effective strategies to prevent and treat hypertension. Development of such strategies relies on a continued evolution of our understanding of the mechanisms which control BP.

\subsection{Factors contributing to the development of hypertension}

Although high BP may be attributable to clear medical conditions, termed secondary hypertension, it remains that no clear cause is evident for around $90 \%$ of people who have high BP (Lloyd-Jones et al., 2005; Messerli et al., 2007). This type of hypertension is called primary or essential hypertension. It has long been accepted that BP is a quantitative trait with continuous variation, pointing to multiple factors influencing the level of human BP (Pickering, 1972; Deng, 2007). It is clear that lifestyle can have a very important impact on hypertension and cardiovascular health, and, as there are numerous publications in this area, this will not be considered further in this review. However, it is also apparent that BP has a heritable component of about $15-60 \%$; such a range being dependent on whether in-clinic or ambulatory measures of BP are studied (Mongeau, 1989; Kotchen et al., 2000; Kupper et al., 2005; Zuk et al., 2012). Whilst, from a pharmacological point of view, it is important to understand the underlying molecular mechanisms which contribute to the development of essential hypertension, this is confounded by the complex nature in which potentially multiple susceptibility genes are themselves modulated by environmental factors and interactions with other genetic loci (O'Shaughnessy, 2001).

Recent advances in genetic sequencing technology have enabled investigations to determine whether specific genetic factors can confer susceptibility to disease. Genome wide association studies (GWAS) in multiple different ethnic populations have revealed at least 52 distinct genetic variants with significant association to BP and/or hypertension (McCarthy et al., 2014; Tragante et al., 2014). Each individual variant appears to only have a modest direct effect on $\mathrm{BP}$ (less than $1 \mathrm{mmHg}$ per allele for systolic pressure), so, even collectively, these loci may only provide a minor contribution to the known percentage heritability of $\mathrm{BP}$ (Johnson et al., 2011; McCarthy et al., 2014). Therefore, it appears more genes, pathways or gene-environment interactions remain to be elucidated to more fully describe the genetic basis of essential hypertension. Whilst such associations can highlight new targets for possible regulation of BP, physiologically testing the function of genes within target loci is a key requirement for confirming whether a gene within, or part of, a loci of association is indeed part of a pathway which can influence BP.

\section{Resistance arteries and essential hypertension}

BP is the product of cardiac output and total peripheral resistance. Although cardiac output and sympathetic activity may be elevated in the early stages of hypertension, increased peripheral resistance is the main driver for chronically elevated BP (Heagerty et al., 2010). Resistance to flow can be influenced by blood viscosity, vessel length and vessel diameter, with resistance being inversely proportional to the fourth power of the vessel's radius (Poiseuille's law) (Badeer, 2001; Sriram et al., 2014). Small arteries which provide the greatest percentage contribution to peripheral resistance have been termed resistance arteries, and are defined as pre-capillary vessels composed of a relatively thick media layer and having internal diameter of approximately 100-300 $\mu \mathrm{m}$ (Mulvany \& Aalkjaer, 1990; Korsgaard et al., 1993; Christensen \& Mulvany, 2001; Heagerty et al., 2010). As resistance 
arteries play a key role in regulating peripheral vascular resistance, the structure and contractility of these vessels are crucially important factors in determining and regulating BP. Importantly, changes in both the structure and function of resistance arteries are believed to play an essential role in the development and progression of hypertension (Heagerty et al., 2010; Rizzoni \& Agabiti-Rosei, 2012).

\subsection{Resistance artery structure and hypertension}

It is well established that structural changes in resistance arteries are associated with chronically elevated BP (Heagerty et al., 2010; Rizzoni et al., 2011; Mulvany, 2012). There is now significant evidence to support the notion that high BP is associated with a remodelling of resistance arteries such that there is a thickening of the medial layer of the arterial wall of resistance arteries, a reduced lumen diameter and thus an increased media to lumen ratio (Korsgaard et al., 1993; Martinez-Lemus et al., 2009; Rizzoni \& Agabiti-Rosei, 2012; Renna et al., 2013). Although growth may be evident in certain pathologies and in advanced hypertension (Rizzoni et al., 1996), there is now a wealth of evidence to suggest that inward remodelling of resistance arteries with no significant change in cross sectional area, termed eutrophic remodelling, is a key feature of essential hypertension, and underpins elevated peripheral resistance (Heagerty et al., 1993; Izzard et al., 2005; Heerkens et al., 2006; Staiculescu et al., 2013). Eutrophic remodelling of resistance arteries is proposed to be a consequence of realignment and potentially closer associations between vascular smooth muscle cells (VSMCs) of the arterial wall, and not hypertrophy and/or hyperplasia of VSMCs, generating a detectable narrowing in lumen diameter of the vessel (Heagerty et al., 2010), Fig. 1.

There are now numerous studies which support the notion that changes in small artery structure have strong prognostic significance in hypertensive patients, over and above all other known cardiovascular risk factors (Rizzoni et al., 2003; De Ciuceis et al., 2007; Mathiassen, Buus, et al., 2007b). Understanding the mechanisms which may modulate resistance arterial eutrophic remodelling is thus important, but these remain poorly understood. Prolonged vasoconstriction appears important, which, in itself may modulate re-organisation via the activities of cross-linking enzymes such as tissue-type transglutaminase and/ or integrins (Bakker et al., 2002, 2005; Heerkens et al., 2006). It has been proposed that initial eutrophic remodelling may be an energetically favourable adaptive mechanism to normalise wall stress to maintain adequate blood flow, whilst a growth response, which may be observed in advanced or secondary hypertension, is related to a greater adverse prognosis (Izzard et al., 2006; Heagerty et al., 2010).

It is important to note that in essential hypertension the relationship between BP and remodelling remains unclear. Whilst some studies suggest that structural changes follow a change in BP and/or prolonged arterial vasoconstriction (Bakker et al., 2002), there is evidence from

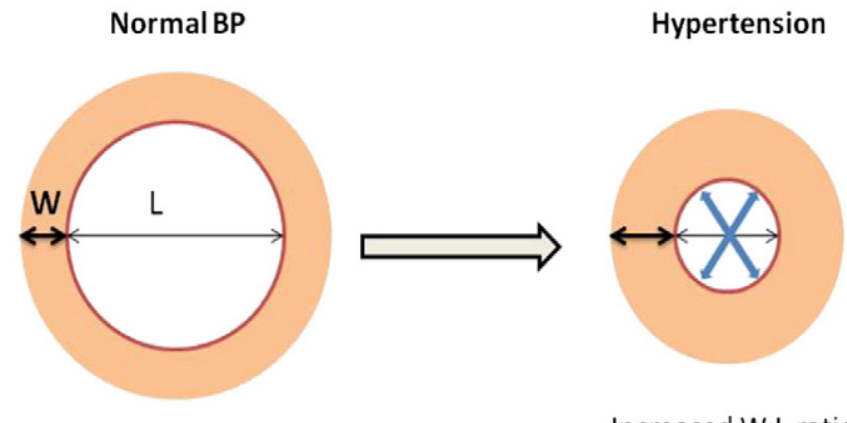

Fig. 1. Eutrophic remodelling of resistance arteries. Increased intraluminal pressure $(\boldsymbol{})$ is associated with cellular rearrangement, principally of VSMCs, resulting in a narrower lumen diameter (L) and increased wall thickness (W) of the vessel. studies using genetically modified mice that structural changes may precede the development of hypertension (Zacchigna et al., 2006). Whilst studies on isolated arteries from animal models of hypertension suggest that remodelling may be a consequence of reduced resistance arterial distensibility (at least in the cerebral circulation) (Izzard et al., 2006), others have shown increased distensibility (Laurant et al., 1997). Thus, there is little to support changes in distensibilty of resistance arteries being the primary driver for remodelling in all vascular beds. Therefore, debate on this topic continues; hence, further understanding of how arterial remodelling may be initiated and progresses in relation to a change in BP is important for elucidating the factors contributing to the development and progression of high BP.

\subsection{Arterial contractility and hypertension}

The contractility of resistance arteries is important in setting peripheral vascular resistance, and thus BP. Whilst enhanced arterial constriction will, in itself, increase vascular resistance, it appears that the major consequence of altered levels of contractile activation in hypertension is on arterial remodelling. Studies on isolated rat small arteries maintained in culture have shown that chronic vasoconstriction itself induces eutrophic remodelling and that this remodelling is independent of the vasoconstrictor stimulus (Bakker et al., 2000, 2002, 2004). Furthermore, chronic in vivo infusion of vasoconstrictor stimuli in animals has also been shown to induce remodelling (Eftekhari et al., 2007). Enhanced contraction may occur as a result of changes in external stimuli and/or due to underlying contractile mechanisms. Although elevated sympathetic activity, increased sensitivity to vasoactive stimuli (Angus et al., 1992) and increased myogenic tone (Izzard et al., 1996) have been shown to be involved in the development of hypertension in some vascular beds, such changes do not appear to persist when hypertension is established (Izzard et al., 1996, 2006). There is much debate in the literature about whether structural changes amplify vasoconstrictor responses (Wright \& Angus, 1999; Folkow, 2000; Korner et al., 2000; Izzard et al., 2002), hence the relationship between active tone and remodelling remains to be fully elucidated. Nevertheless, it is generally accepted that changes in contractility of some resistance arteries play a key role in remodelling during the development of hypertension. In support of this it has been shown that normalisation of vascular structure by anti-hypertensive therapies was independent of BP but was dependent on vasodilatation (Mathiassen, Buus, et al., 2007a; Mulvany, 2012). Thus, it is important to further understand the mechanisms which modulate resistance arterial contractility in both the developing and sustained phases of hypertension.

Arterial tone is principally regulated via the contractile state of VSMCs. This can be modulated by stimuli acting directly on the VSMCs or by those acting on the vascular endothelium which lines the lumen of blood vessels. The endothelium modulates arterial tone by the release of and/or stimulation of powerful vasodilating and vasoconstricting factors, principally nitric oxide (NO), prostacyclin and endothelium derived hyperpolarising factor (Furchgott \& Zawadzki, 1980; Mombouli \& Vanhoutte, 1999; Feletou \& Vanhoutte, 2009). NO is a powerful vasodilator and is synthesised via nitric oxide synthase (NOS) of which three forms exist; endothelial NOS (eNOS) primarily from endothelial cells; neuronal NOS (nNOS) which is expressed in peripheral nitrergic nerves innervating smooth muscle and also reported in aortic VSMCs; and inducible NOS (iNOS)-the source of which is not clear in the vasculature ((Forstermann et al., 1995; Furchgott \& Zawadzki, 1980); H. (Schwarz et al., 1999; Li et al., 2002)). NO induces dilation via activation of cyclic guanosine monophosphate (cGMP)-mediated pathways (Waldman \& Murad, 1987; Bolotina et al., 1994; Ignarro, 2002). cGMP appears to be important in BP regulation as global ablation of cGMP results in increased conscious BP (Pfeifer et al., 1998).

Endothelial dysfunction has been reported in numerous disease states including in hypertensive rodents and has also been proposed to occur in old hypertensive patients (Fujii et al., 1992; Taddei et al., 
1997; Vanhoutte et al., 2005; Taguchi et al., 2015), however, this is not a uniform finding (Li \& Bukoski, 1993). Indeed, in some studies endothelium-dependent relaxation of resistance arteries has been reported to be preserved in hypertension by an NOS-dependent mechanism (Kang et al., 2007). Other studies have shown that abnormal endothelial function in small blood vessels does not predict cardiovascular events in patients with essential hypertension (Rizzoni et al., 2006) and indeed such dysfunction appears to be independent of vascular structural changes in hypertension (Rizzoni et al., 1998). There continues to be debate as to the role of the endothelium in the development and progression of hypertension (Luscher, 1994), nevertheless, the endothelium is an important modulator of vascular contractility and BP which should not be ignored when developing new therapeutic targets for hypertension.

\subsection{Mechanisms controlling arterial contractility; role of intracellular free calcium}

It is ultimately the contractile state of vascular smooth muscle which determines the level of vascular tone. As such, it is important to understand the underpinning mechanisms which mediate smooth muscle contractility.

The concentration of intracellular free calcium $\left(\left[\mathrm{Ca}^{2+}\right]_{i}\right)$ underpins the modulation of VSMC contractility and thus arterial diameter and vascular resistance. An increase in $\left[\mathrm{Ca}^{2+}\right]_{\mathrm{i}}$ results in activation of myosin light chain kinase (MLKC), subsequent phosphorylation of myosin, and VSM contraction. Conversely, a fall in $\left[\mathrm{Ca}^{2+}\right]_{\mathrm{i}}$ results in activation of myosin light chain phosphatase and dephosphorylation of myosin, hence promoting arterial relaxation (Somlyo \& Somlyo, 1994; Gollasch et al., 2000; McCarron et al., 2006). [ $\left.\mathrm{Ca}^{2+}\right]_{i}$ levels are modulated by either influx/efflux across the plasmalemma and or release/sequestration into intracellular calcium stores predominantly, but not exclusively, the sarcoplasmic reticulum (SR). (Although a brief overview of the main mechanisms is given below a detailed discussion of the mechanisms which modulate calcium homeostasis in smooth muscle is beyond the scope of this text and as such we direct the reader towards reviews of this area for more information (Amberg \& Navedo, 2013; Hill-Eubanks et al., 2011; Kudryavtseva et al., 2013)). The relationship between $\mathrm{Ca}^{2+}$ and contraction is, however, not straightforward and it is now evident that subcellular $\mathrm{Ca}^{2+}$ fluxes and microdomains exist which may differentially modulate contractile function (Gollasch et al., 2000; McCarron et al., 2006). Whilst an increase in global $\left[\mathrm{Ca}^{2+}\right]_{\text {i }}$ promotes arterial contraction, localised increases in $\mathrm{Ca}^{2+}$ may have different effects on contraction. For example, in isolated myogenic cerebral arteries, local increases in intracellular calcium following activation of ryanodine receptors on the SR cause arterial vasodilation via activation of $\mathrm{Ca}^{2+}$-activated potassium channels (Nelson et al., 1995). In contrast, in isolated retinal arteries it has been shown that $\mathrm{Ca}^{2+}$ sparks can promote myogenic tone, most likely via summation to generate $\mathrm{Ca}^{2+}$ waves/oscillations (Tumelty et al., 2007; Kur et al., 2013). Although modulation of the calcium sensitivity of the contractile apparatus can regulate VSMC contractility (Kimura et al., 1996; Uehata et al., 1997; Andre et al., 2014; Takeya et al., 2014) it is clear that regulating $\left[\mathrm{Ca}^{2+}\right]_{\mathrm{i}}$ within VSMCs plays a crucial role in regulating the contractile state of VSMCs, and hence vascular resistance and thus BP. As such, factors which modulate $\mathrm{Ca}^{2+}$ homeostasis in vascular smooth muscle are particularly attractive therapeutic targets for BP reduction and potential reversal of inward remodelling in resistance arteries.

$\mathrm{Ca}^{2+}$ influx into VSMCs is principally driven by plasma membrane voltage gated $\mathrm{Ca}^{2+}$ channels (VGCC), particularly L type $\mathrm{Ca}^{2+}$ channels. Though, notably, increased $\left[\mathrm{Ca}^{2+}\right]_{i}$ can be promoted by activation of $\mathrm{Ca}^{2+}$ release channels, including ryanodine receptors and inositol 1,4,5-trisphosphate receptors on the SR, and also via transient receptor potential (TRP) channels (Jackson, 2000; Parekh \& Putney, 2005; Earley et al., 2007; Gonzalez-Cobos \& Trebak, 2010). There is evidence to suggest that high BP can modulate activation of calcium channels via changes in their expression level or by affecting their functional ionic conductance (Stekiel et al., 1986; Pesic et al., 2004). Such effects can exacerbate vasoconstriction and elevate vascular resistance and BP; hence, treatment strategies to reduce high $\mathrm{BP}$ have long involved the use of Ltype VGCC inhibitors (Sonkusare et al., 2006). Further, $\mathrm{Ca}^{2+}$ channel blockers which dilate resistance arteries have been shown to reverse eutrophic remodelling (Schiffrin, 2004; Agabiti-Rosei \& Rizzoni, 2010). Taken together this suggests that therapies which target intracellular calcium homeostasis are worthy of exploration. This should also include investigation into mechanisms which reduce levels of intracellular $\mathrm{Ca}^{2+}$ and could stimulate arterial dilation. These mechanisms include sequestration into intracellular stores, most notably into the SR via its $\mathrm{Ca}^{2+}$ ATPase pump (SERCA), and via extrusion across the plasma membrane. The activity of SERCA is regulated by phospholamban (PLN); aortic contractions from PLN-deficient mice have been shown to be reduced, effects which were abolished by pharmacological SERCA inhibitors (Lalli et al., 1997; Oloizia \& Paul, 2008). Thus, modulation of mechanisms which decrease cytoplasmic $\mathrm{Ca}^{2+}$ can modulate arterial contractility and may thus be a potential target for reduction of $\mathrm{BP} \mathrm{Ca}^{2+}$ can be extruded out of VSMCs by two different $\mathrm{Ca}^{2+}$ transporting systems, the $\mathrm{Na}^{+} / \mathrm{Ca}^{2+}$ exchanger (NCX), predominantly type 1 (NCX1) (Quednau et al., 1997), and plasma membrane calcium ATPase type 1 or 4 (PMCA1, PMCA4) (Oloizia \& Paul, 2008). In the heart, NCX plays a major role in $\mathrm{Ca}^{2+}$ extrusion extruding one $\mathrm{Ca}^{2+}$ out of the cell in exchange for three $\mathrm{Na}^{+}$ions (Bers, 2000). In VSMCs, however, it is bidirectional and can modulate $\mathrm{Ca}^{2+}$ efflux or influx depending on the relative concentrations of $\mathrm{Ca}^{2+}$ and $\mathrm{Na}^{+}$(Blaustein \& Lederer, 1999) and its role in $\mathrm{Ca}^{2+}$ extrusion has been questioned (Kamishima \& McCarron, 1998). Indeed smooth muscle-specific genetic ablation of NCX1 lowers BP (Zhang et al., 2010; Zhao et al., 2011), whilst, conversely, mice overexpressing NCX1 in smooth muscle display increased BP (Blaustein \& Lederer, 1999; Iwamoto et al., 2004); effects not consistent with a predominant role in $\mathrm{Ca}^{2+}$ extrusion. Currently there is little known about the specific contribution of PMCAs to $\mathrm{Ca}^{2+}$ efflux in VSM, but in bladder and myometrial smooth muscle extrusion by this route has been reported to contribute approximately $30 \%$ and $70 \%$ of total calcium efflux respectively (Matthew et al., 2004; Liu et al., 2006). Therefore, a greater understanding of the role of PMCAs in the microcirculation is important for further understanding of the regulation of BP and how it might be pharmacologically modulated.

\section{Plasma membrane calcium ATPases}

PMCAs are 10 transmembrane domain ATP-dependent pumps of the P-type family. Four separate PMCA proteins, 1-4, are evident in mammals with each being expressed from its respective gene (i.e. ATP2B1 gene encodes PMCA1 protein). Numerous splice variants of each gene have been found to be functionally expressed, with the possibility that over 30 variants can be generated (Keeton et al., 1993; Di Leva et al., 2008). The $N$ and $C$ termini of PMCA are both intracellular, with the far longer $\mathrm{C}$ terminus containing regulatory domain binding sites and PDZ domains physically linking to interacting partners (James et al., 1988; Kessler et al., 1992; Hofmann et al., 1993; Di Leva et al., 2008). Extracellular loops are believed to be of minimal length (Di Leva et al., 2008), Fig. 2.

PMCA1 is ubiquitously expressed in humans; ablation of PMCA1 is embryonically lethal early in mouse development leading to the suggestion that the protein has a 'housekeeping' or developmental role (Okunade et al., 2004; Brini, 2009; Kenyon et al., 2010). PMCA4 is also present in most cell types, but its function may be more tissue specific than PMCA1 (Schuh et al., 2004). Tissue expression of PMCA2 and PMCA3 is far more limited, with their main functional role being in neuronal cells and the ear (Kozel et al., 1998). PMCA1 and PMCA4 are both present in the vasculature and thus have the potential to contribute to vascular structure and function. 


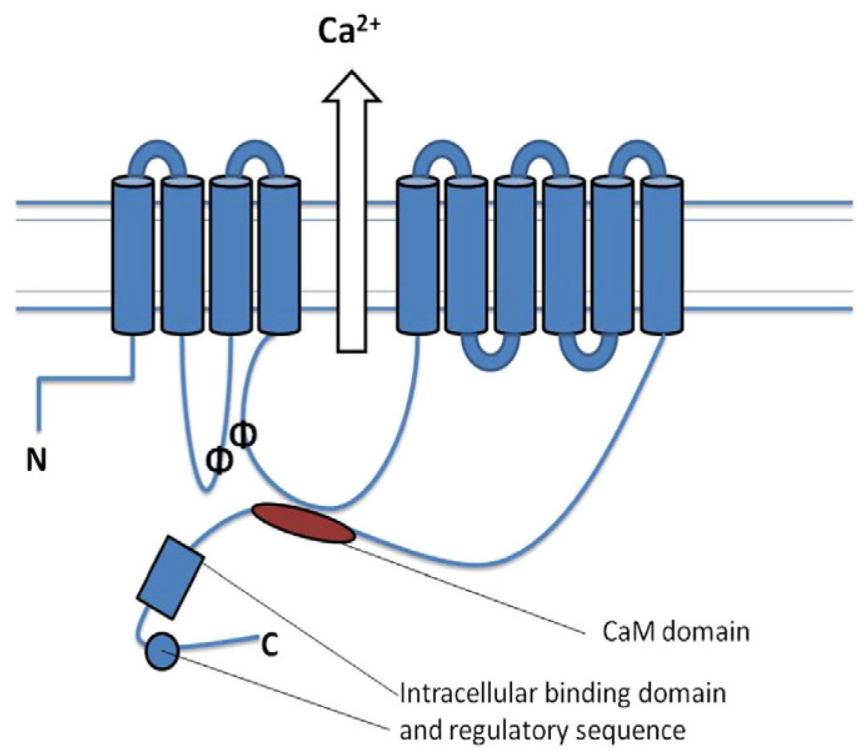

Fig. 2. Schematic representation of the transmembrane positioning of the PMCA protein. The 10 transmembrane domain structure of mammalian PMCA. $\mathrm{N}$ and $\mathrm{C}$ termini for both PMCA1 and 4 are intracellular. ATP binding to the catalytic domain $(\Phi)$ promotes $\mathrm{Ca}^{2+}$ efflux, which is modulated by the autoinhibitory $\mathrm{Ca}^{2+}$-calmodulin binding domain (CaM).

\subsection{Expression of plasma membrane calcium ATPases in the vasculature}

PMCAs have been shown to be present in both VSMCs and endothelial cells and can thus potentiate vascular function via actions on either of these cells types. PMCA1 RNA has been detected in pig aortic smooth muscle and endothelial cells (Pande et al., 2006), whilst mRNA for PMCA1 has also been detected in rat cultured aortic VSMCs (Sasamura et al., 2002). At the protein level, PMCA1 is present in VSMCs from mouse aorta (Kobayashi et al., 2012), as well as in endothelial cells from the pig coronary artery (Szewczyk et al., 2007).

PMCA4 mRNA has been detected in endothelial and VSMCs of porcine aorta (Szewczyk et al., 2007), in VSMCs from mouse carotid artery (Afroze et al., 2014), and was shown as the most prominent PMCA mRNA transcript in mouse whole aorta (Okunade et al., 2004). PMCA4 protein expression has been reported in a mouse VSMC line (Afroze et al., 2003) and in isolated murine aortic VSMCs (Momen et al., 2014).

Although it is clear that both PMCA1 and PMCA4 are present in the vasculature their relative expression is difficult to quantify. However, Pande and colleagues have suggested that PMCA4 is the dominant form in pig aortic VSMCs (Pande et al., 2006). In contrast, others have shown that mRNA for PMCA1 is more prevalent than that for PMCA4 in rat cultured aortic VSMCs, with PMCA4 transcripts suggested to be at only a quarter of the level of those for PMCA1 (Sasamura et al., 2002). In porcine aortic endothelial cells PMCA1 RNA has been shown to be detectable at a higher level than PMCA4 transcripts (Pande et al., 2006; Szewczyk et al., 2007). Thus, the vascular expression of PMCA1 and 4 may be species specific, with further work being required to clearly determine the relative expression of PMCA1 and PMCA4 in VSMCs and endothelial cells, particularly in resistance arteries.

\section{Plasma membrane calcium ATPase 1, arterial contractility and blood pressure regulation}

Although multiple factors underpin the development of essential hypertension, heritability of 30-60\% may combine with other risk factors to potentiate disease development (Miall \& Oldham, 1963; Kupper et al., 2005). As such, there has been a long standing search for genetic components of hypertension. Advances in genome sequencing technology, determining quantitative trait loci by assessing single nucleotide polymorphisms (SNPs) in disease relative to control cohorts, have, relatively recently, highlighted genomic regions which may contribute as single factors in BP regulation. Crucially, a genomic region containing ATP2B1, which encodes for PMCA1, has been identified as having a very strong association with BP variance and/or with hypertensive disease in different human population groups (Cho et al., 2009; Levy et al., 2009; Hong et al., 2010; Takeuchi et al., 2010; Johnson et al., 2011). Importantly, SNPs associating ATP2B1 with BP have attained genome wide significance in replication analyses in multiple different ethnic groups and have shown a consistently high level of genetic association (Tabara et al., 2010; Miyaki et al., 2012; Xi et al., 2012; Ganesh et al., 2013; Wang et al., 2013). SNPs relating to ATP2B1 in a Japanese cohort were found to give an odds ratio of 1.17 to 1.31 for hypertension (Tabara et al., 2010), a very similar level of risk as reported by other large scale GWAS. More recently ATP2B1 has been genetically linked with pulse pressure (Kelly et al., 2013) and to coronary artery calcification and myocardial infarction in chronic kidney disease (Ferguson et al., 2013), further substantiating a possible genetic link to cardiovascular function. How ATP2B1 may be associated with cardiovascular function cannot be directly determined by GWAS. Detection of SNPs associated with hypertension in the promoter region of ATP2b1 (Cho et al., 2009; Tabara et al., 2010) could suggest that it is modulation of gene expression which may drive a BP phenotype. Furthermore, ATP2b1 mRNA expression has been reported to be reduced in human umbilical artery smooth muscle cells from people carrying risk alleles as determined by GWAS (Tabara et al., 2010). However, with ATP2b1 genomic regions also having been shown to be associated with hyperlipidemia and diabetes (Heo et al., 2014), the potential role of PMCA1 in BP regulation may additionally be due to indirect effects on metabolism.

Thus, there is accumulating evidence to support an important role for ATP2b1 in BP regulation. It should, however, be noted that genome linkage analysis is correlative and does not definitively demonstrate a cause-effect relationship between a genomic region and a BP phenotype (Deng, 2007). Therefore, it has been paramount to physiologically link PMCA1 to a BP phenotype to clearly show the protein can indeed functionally regulate $\mathrm{BP}$.

Genetically modulated animal models are widely used to directly investigate the effect of changes in gene and protein expression on physiological function. Global ablation of Atp $2 b 1$ in mice is embryonically lethal early in development, between 3.5 and 8.5 days of pregnancy, suggesting an important role for PMCA1 in development (Okunade et al., 2004; Shaheen, 2012). PMCA1 has been proposed to have a role in BP regulation as mice bred to be globally heterozygous for Atp2b1, whilst indeed viable, exhibit elevated BP (Fujiwara et al., 2014). Elevated peripheral BP was also reported in mice following injection of siRNA constructs to block production of PMCA1 protein (Shin et al., 2013). Studies using mice with VSMC specific deletion of PMCA1, generated using the Cre-loxP system, support a specific role in the vasculature for Atp2b1. Whilst the gross phenotype and survival of these mice were unaffected, they did exhibit significantly elevated systolic BP (Kobayashi et al., 2012).

Femoral arteries from mice devoid of VSM PMCA1 protein exhibited enhanced contractility to phenylephrine (Kobayashi et al., 2012), whilst studies using heterozygous Atpb1 mice demonstrated both an increased contractility to phenylephrine and a reduced endothelium-dependent dilation to acetylcholine from isolated abdominal aorta vascular rings (Fujiwara et al., 2014). Similarly, elevated BP following silencing of Atp2b1, has been associated with enhanced isolated small artery contractility to phenylephrine and increased myogenic responsiveness (Shin et al., 2013). Importantly, siRNA knockdown of Atp2b1 has been associated with an increased media:lumen ratio in mesenteric resistance arteries, characteristic of essential hypertension (Shin et al., 2013). Thus there is now substantial evidence to support an involvement of PMCA1 in BP regulation, in part at least, via effects on the structure and function of small arteries. 
The mechanisms whereby modifications in the expression of Atp2b1/PMCA1 can modulate arterial structure and function still require further elucidation; however, as PMCA1 is a $\mathrm{Ca}^{2+}$ extrusion pump one potential way is clearly by modulation of global $\left[\mathrm{Ca}^{2+}\right]_{\mathrm{i}}$. In support of this, cultured VSMCs from smooth muscle-specific PMCA1 deleted mice exhibited elevated levels of basal $\left[\mathrm{Ca}^{2+}\right]_{i}$ and also in response to phenylephrine stimulation (Kobayashi et al., 2012). However, evidence from heterozygous PMCA1 mice shows that PMCA1 can also modulate arterial tone via effects on NO, effects attributed to a reduced phosphorylation of eNOS (residue Ser-1177) and production of NO (Fujiwara et al., 2014). Endothelial cells from heterozygous Atp2b1 mice exhibit reduced expression of eNOS, with no significant difference in nNOS expression being reported (Fujiwara et al., 2014). A functional interaction between PMCA1 and eNOS has been demonstrated in human endothelial cells, however, in contrast to animal studies, PMCA1 appears to be a negative regulator of eNOS primarily via increased phosphorylation of Thr-495 of eNOS; Thr-495 being an inhibitory residue (Holton et al., 2010). There is clearly a need for further study to elucidate the effects of PMCA1 on eNOS activity, endothelial function and subsequent effects on the resistance vasculature and on BP. Also It should be noted that the effects of PMCA1 on other endothelial factors also needs to be established especially as NO generally plays a smaller role in resistance arteries than it does in large arteries (Urakami-Harasawa et al., 1997).

Thus, there is now increasing evidence for a clear link between Atp2b1/PMCA1 and BP, effects which can be modulated by changes in arterial contractility. Effects of PMCA1 in VSMCs and on global $\left[\mathrm{Ca}^{2+}\right]_{i}$ are consistent with a major role for PMCA1 in $\mathrm{Ca}^{2+}$ extrusion, whilst how PMCA1 may be involved in arterial remodelling requires further investigation. Further work is clearly required to elucidate the different ways in which PMCA1 may modulate arterial contraction. To date, data on only one relatively selective inhibitor of PMCA1, the small peptide caloxin 1b3, has been published (Szewczyk et al., 2010). Caloxin $1 \mathrm{~b} 3$ has been reported to be selective for PMCA1 in rabbit duodenal mucosa and pig coronary artery endothelial cells, and has been shown to increase $\left[\mathrm{Ca}^{2+}\right]_{\mathrm{i}}$ in these endothelial cells (Szewczyk et al., 2010). However, the influence of caloxin 1b3 on arterial contractility and BP remains to be clearly determined. Nevertheless, the strong clinical evidence of an association between ATP2B1 and BP, coupled with experimental studies directly linking changes in PMCA1 expression to increases in resistance arterial contractility and increased BP, make PMCA1 a very attractive potential therapeutic target which warrants further exploration.

\section{Plasma membrane calcium ATPase 4 in blood pressure regulation}

Although there is a wealth of clinical evidence suggesting a role for PMCA1 in BP regulation there is also substantial evidence from experimental studies which show that changes in the expression of PMCA4 can also modulate arterial contractility and BP. To date, two investigative approaches have been taken; 1) studies employing transgenic overexpression of PMCA4 in vivo and 2) pharmacological inhibition of PMCA4.

\subsection{Transgenic expression of plasma membrane calcium ATPase 4}

Studies conducted by Gros and colleagues and Schuh and colleagues over a decade ago provided the first evidence that PMCAs can modulate arterial contractility and BP (Gros et al., 2003; Schuh et al., 2003). Both groups generated transgenic mice overexpressing human PMCA4b, either under control of vascular-specific SM $22 \alpha$ promoter or doxycycline-induced overexpression in smooth muscle, (Gros et al., 2003; Schuh et al., 2003). Perhaps surprisingly, both transgenic mouse models exhibited an increase in BP. The elevated BP was accompanied by enhanced aortic contraction to $\mathrm{K}^{+}$-mediated membrane depolarisation (Schuh et al., 2003), plus heightened myogenic tone and elevated response to adrenergic stimulation in mesenteric arteries (Gros et al., 2003). These effects are not consistent with PMCA4 acting as a major contributor to removal and modulation of global $\left[\mathrm{Ca}^{2+}\right]_{\mathrm{i}}$. Indeed, it has been shown that basal arterial VSMC $\left[\mathrm{Ca}^{2+}\right]_{\mathrm{i}}$ was comparable in both PMCA4 overexpressing and control mice (Gros et al., 2003). The changes in arterial contractility in both animal models were prevented by inhibition of nNOS pointing to negative regulation of nNOS activity by PMCA4 (Gros et al., 2003; Schuh et al., 2003). Previous studies in human endothelial cells have shown that PMCA4 interacts with eNOS leading to increased phosphorylation at Thr-495 and reduced enzymatic activity (Holton et al., 2010). However, in aortae at least, endothelium-dependent relaxation to acetylcholine was unaffected by overexpression of PMCA4 (Schuh et al., 2003). Although it is important that the effects of PMCA4 overexpression on endothelial function in resistance arteries are investigated, results so far, together with the fact that NO plays a lesser role in endothelium-dependent dilation in resistance arteries when compared to large arteries (UrakamiHarasawa et al., 1997), suggest that the endothelium does not play a major role in the effects of PMCA4 on modulation of arterial contraction and BP. To date, no published studies have looked at the effects of genetic ablation of Atp2b4 (for PMCA4 protein) on resistance arterial structure or function.

It is now evident that PMCA4 has a major role in signal transduction in a number of excitable cells. In isolated molecular experiments, cardiomyocytes and whole heart tissue PMCA4 functionally associate with calcineurin (Buch et al., 2005), Ras-associated factor 1 (Armesilla et al., 2004), $\alpha 1$-syntrophin (Williams et al., 2006) and nNOS, the latter via interaction with the PDZ domain on PMCA4 (Schuh et al., 2001; Oceandy et al., 2007; Duan et al., 2013). In blood vessels any such association of PMCA4 and nNOS clearly appears to be of relevance to the regulation of arterial contractility. It is well known that NO can influence contractility of peripheral blood vessels, and it is becoming more apparent that vascular NO production is not just mediated by eNOS but also via nNOS activity (Kaley et al., 1992; Buchwalow et al., 2002; Webb et al., 2006). nNOS-mediated NO production in a cellular assay has been shown to be significantly reduced when the enzyme is tethered as part of a macromolecular complex including PMCA4, confirming that PMCA4 is a negative regulator of nNOS activity (Schuh et al., 2004). The exact way in which PMCA4 modulates vascular nNOS activity is unknown, but nNOS activity is calcium/calmodulin dependent and a role for PMCA4 in regulating localised $\mathrm{Ca}^{2+}$ concentrations in a microdomain has been suggested (Cartwright et al., 2007). More recent investigation of the role of PMCA4 in cardiac signalling has supported this supposition, pointing to PMCA4 having an important role as a structural molecule in the heart (Oceandy et al., 2007; Mohamed et al., 2011). Overexpression of PMCA4 in arterial smooth muscle has been shown to significantly reduce nNOS activity (Gros et al., 2003). Hence, reduced production of vasodilatory NO has been proposed in explanation for elevated BP observed in PMCA4 overexpressing mice (Gros et al., 2003; Schuh et al., 2003). Thus, studies from transgenic overexpressing mice suggest that PMCA4 is a powerful modulator of BP and that changes in resistance arterial contractility, as a result of negative regulation of nNOS by PMCA, are likely contributors to this. However, a different role for PMCA4 in the vasculature has been proposed following a different experimental approach: that of pharmacological inhibition of PMCA4 using caloxin peptides (Chaudhary et al., 2001).

\subsection{Pharmacological modulation of plasma membrane calcium ATPase 4 activity}

The role of PMCA4 in the vasculature has been further assessed pharmacologically by using caloxin peptides, which have been designed to inhibit the protein's ability to pump $\mathrm{Ca}^{2+}$. A number of caloxin compounds have been designed, with screens against PMCA4 identifying caloxin $1 \mathrm{~b} 1$ as an inhibitor of PMCA4 $\left(\mathrm{K}_{\mathrm{i}}=46 \pm 5 \mu \mathrm{M}\right.$ compared $\mathrm{K}_{\mathrm{i}}=105 \pm 11 \mu \mathrm{M}$ for PMCA1) (Pande et al., 2006). By binding to the 
first extracellular domain of PMCA4 it is proposed that caloxin 1b1 inhibits $\mathrm{Ca}^{2+}$ flux non-competitively by blocking/altering the required conformational change in the protein which occurs with the binding of ATP (Holmes et al., 2003; Pande et al., 2006).

Although the effects of caloxin 1b1 on BP have not been investigated, acute application has been shown to increase contraction of rat aortic rings in response to agonist stimulation (Pande et al., 2006). Furthermore, caloxin $1 \mathrm{~b} 1$ has been shown to potentiate increased $\left[\mathrm{Ca}^{2+}\right]_{\mathrm{i}}$, promoted by $\mathrm{Ca}^{2+}$ ionophore application in cultured arterial VSMCs derived from porcine aorta (Pande et al., 2006). Subsequently caloxin $1 \mathrm{c} 2\left(\mathrm{~K}_{\mathrm{i}}=2.3 \pm 0.3 \mu \mathrm{M}\right)$, a more selective PMCA4 inhibitor with ten-fold greater selectivity for PMCA4 over other PMCAs, has been shown to increase the basal tone of isolated coronary arteries and the force of their contraction compared to control tissues at low extracellular $\mathrm{Ca}^{2+}$ levels $\left(\left[\mathrm{Ca}^{2+}\right] \mathrm{o}\right)(<1.6 \mathrm{mM})$ whilst in the presence of inhibition of NCX and SERCA (Pande et al., 2008). Thus, available evidence to date as to the effects of caloxins correlates with the expectation that inhibiting a $\mathrm{Ca}^{2+}$ extrusion pump would elevate $\left[\mathrm{Ca}^{2+}\right]_{\mathrm{i}}$ in PMCA4 expressing VSMCs and contribute to augmented vascular contractility and BP. It is however important to highlight that previous studies have only explored the effects of caloxins on larger arteries, namely coronary arteries and the aorta, which do not make significant contributions to overall vascular resistance and BP (Pande et al., 2006, 2008). There is thus a pressing need to explore the effects of PMCA4 inhibitors on resistance arteries. The effects of PMCA4 inhibition on endothelium function also need to be elucidated.

As previously discussed, regulation of $\left[\mathrm{Ca}^{2+}\right]_{\mathrm{i}}$ in vascular cells is important for determining arterial tone and vessel contractility. Whilst the effects of caloxins point to a role for PMCA4 in BP regulation, inhibiting the $\mathrm{Ca}^{2+}$ extrusion pumping capability of PMCA4 seems inappropriate for a novel direct anti-hypertensive drug. However, other factors relating to tissue perfusion may also be considered, as PMCA4 has been proposed as an endogenous regulator of processes leading to angiogenesis (Baggott et al., 2014). Hence, there is a requirement for further understanding of the effects of inhibiting PMCA4 and also development of new drugs against the protein.

We have recently identified aurintricarboxylic acid (ATA) as a novel inhibitor of PMCA4, being capable of fully inhibiting PMCA4 at $1 \mu \mathrm{M}$ (Mohamed et al., 2013). In vitro, ATA was found to have a dose dependent effect on PMCA4 ( $\mathrm{IC}_{50}$ approximately $150 \mathrm{nM}$ ), and have only a very minor effect on PMCA1 and SERCA with no inhibitory effect on the $\mathrm{Na}^{+} / \mathrm{K}^{+}$ATPase (Mohamed et al., 2013). Thus, we propose that ATA, with its high level of selectivity over other PMCA isoforms and Ptype ATPases, will be a useful tool to further elucidate the effects of PMCA4 in regulating resistance arterial contractility and BP. ATA, however, modulates a variety of different cellular processes. For example, it has been shown to act as a nuclease inhibitor for isolation of nucleic acids (Hallick et al., 1977; Gonzalez et al., 1980), as an inhibitor of the RISC complex hence blocking micro RNA synthesis (Tan et al., 2012) and as a potential inhibitor of glutamate dehydrogenase (Li et al., 2007). It has also been shown to protect cells from human complement-mediated lysis, to reduce tube formation by endothelial cells (Lipo et al., 2013) and to have neuroprotective effects, possibly via inhibition of complement factors of the innate immune system (Lee et al., 2012) or via promoting receptor tyrosine kinase signalling (Okada \& Koizumi, 1995). Whether these effects are due, in part at least, to the effects of ATA on PMCA4 has largely not been considered. Whilst multiple actions of ATA may limit its use as a therapeutic cardiovascular strategy, we have previously discussed that complete inhibition of PMCA4 can be achieved at $1 \mu \mathrm{M}$, a concentration approximately 100 fold lower than which effects on other targets have been reported to occur (Mohamed et al., 2013). Nevertheless, the development of more specific pharmacological tools for PMCA4 is essential to further our understanding of the effects of PMCA4 on resistance arterial contraction and BP.
In summary, available evidence to date suggests that both overexpression and inhibition of PMCA4 increase arterial contractility which may, in turn, increase BP. Whilst it is clear that PMCA4 affects arterial contractility and $\mathrm{BP}$, these effects, and indeed the underpinning mechanisms, may be complex and variable and many questions remain unanswered. Studies to date suggest that PMCA4 may modulate bulk $\mathrm{Ca}^{2+}$ homeostasis, nNOS signalling (Pande et al., 2006, 2008) and eNOS activity (Holton et al., 2010). It is noteworthy that recent studies investigating PMCA4 in the cell cycle have concluded that its role is related both to its activity and its scaffolding effects (Afroze et al., 2014) - this has been demonstrated using two mouse models, one in which there is a complete lack of PMCA4 protein, whilst the other has a mutant, non-functioning PMCA4 (Okunade et al., 2004; Schuh et al., 2004). The availability of the PMCA4 knockout mouse affords the opportunity for investigation of the effects of PMCA4 ablation on BP and arterial contractility. For any clear consensus on the role of PMCA4 in vascular contractility, assessment of a different class of PMCA4 inhibitors, with increased specificity, needs to be made (Pande et al., 2006, 2008; Szewczyk et al., 2008). Indeed, the recent identification of ATA as a highly selective PMCA4 inhibitor (Mohamed et al., 2013) has advanced the pharmacology in this field, and may prove to be a highly useful tool in defining the contribution of PMAC4 to BP regulation.

\section{Treatment strategies and future directions}

In UK clinical practice it is currently recommended that for people aged 55 or older treatment for hypertension focuses on the use of calcium channel blockers as a first step (NICE, 2011). This highlights the fundamental role $\mathrm{Ca}^{2+}$ has for appropriate cardiovascular function. Calcium channel blockers act to inhibit $\mathrm{Ca}^{2+}$ influx into cells; $\mathrm{Ca}^{2+}$ efflux pathways have not previously been considered for the development of BP lowering pharmacology. The resistance vasculature is an important target for anti-hypertensive therapies and indeed elevated cardiovascular risk remains despite a reduction of BP if inward remodelling of the microcirculation is not reversed (Buus et al., 2013). Calcium channel blockers, and indeed other anti-hypertensive therapies (ACE inhibitors, angiotensin II receptor blockers) have beneficial effects on both BP and small artery structure, others, including diuretics, have little effect on arterial structure (Schiffrin, 2004; Agabiti-Rosei \& Rizzoni, 2010). Given the relation to cardiovascular risk, regression of small artery remodelling is an important goal for the development of new anti-hypertensive therapies alongside BP reduction. This may be influenced by changes in resistance arterial contractility (Izzard et al., 1996).

PMCA1 and PMCA4 are the two key PMCAs expressed in cardiovascular tissues. With modulation of both BP and arterial contractility being demonstrated with changes in the expression and/or activity of both PMCA1 (Kobayashi et al., 2012; Shin et al., 2013), and PMCA4 (Gros et al., 2003; Schuh et al., 2003), both have the potential to be new pharmaceutical targets for BP control. The association between ATP2B1 variants and BP variance and/or hypertension in human subjects (Cho et al., 2009; Levy et al., 2009; Hong et al., 2010; Takeuchi et al., 2010; Johnson et al., 2011) suggests that PMCA1 at least may play an important role in the genetic susceptibility to hypertension. Coupled with the recent observation reporting a genetic link between ATP2B1 and resistant hypertension (Fontana et al., 2014), there is thus increasing evidence to support PMCA1 as an attractive target for BP and resistance arterial modulation. It is worth noting that whilst effects of PMCA1 on modulation of BP, arterial structure and intracellular calcium have been demonstrated (Kobayashi et al., 2012) there remains a clear need for investigation into the effects of the protein on resistance arterial remodelling. Equally, the effects of PMCA1 on eNOS and on endothelial function need elucidating. Studies to date suggest that PMCA1 expression/activity is inversely correlated with BP suggestive that a specific activator of the pump would need to be developed to reduce BP. Whilst development of these would undoubtedly be challenging, and remains a concept rather than being actively pursued as a therapeutic 
strategy, a number of natural PMCA activators have been identified which would help inform work in this area (Lopreiato et al., 2014). PMCA activity has been suggested to be increased by acidic phospholipids (Filomatori \& Rega, 2003; Cura et al., 2008). However, PMCAs are not specifically activated by such mechanisms as phosphatidylinositol, and other similar molecules, can also modulate other calcium channels (Kim et al., 2015; Mori et al., 2015). Further, whilst calmodulin binds to an intracellular domain, relieving the autoinhibition on $\mathrm{Ca}^{2+}$ flux as a physiological process for PMCA activation (Fig. 2), it too has actions on other channels, negating it as a target for specifically activating PMCA1 (Choi et al., 2014; Alli et al., 2015).

Studies on PMCA4 overexpressing mice which demonstrate an increase in BP (Gros et al., 2003; Schuh et al., 2003) suggest that development of a pharmacological inhibitor of the protein might be an effective anti-hypertensive therapy. However, previous studies using caloxins to inhibit PMCA4 do not support this as such treatment induces an increase in arterial contractility (Pande et al., 2006). Whilst these studies potentially reveal different mechanisms whereby PMCA4 may modulate contractility there is a clear need for assessment of the effects of caloxins on resistance arteries and indeed the effect of more specific inhibitors of PMCA4 on BP and on arterial structure and function. Indeed a more specific inhibitor of PMCA4 has now been identified (Mohamed et al., 2013) which will provide a useful pharmacological tool for further investigating the effects of PMCA4 inhibition on vascular function and on BP. The experimental approaches used to assess the role played by PMCA1 and PMCA4 in BP regulation and in the vasculature, and current knowledge relating to these is shown in Fig. 3. Further molecular understanding of the actions of PMCAs, at a basic science level, is required before new clinical agents may be developed. Use of new pharmacological tools may highlight possible interventional routes, and indeed may be translated into future new antihypertensive therapies.

In summary, whilst strategies to reduce weight and promote a healthy lifestyle do, and will continue to, successfully reduce BP in some patients, new pharmacological therapies are required to treat chronic hypertension which still persists in significant numbers of individuals. Although further work is required to elucidate the precise

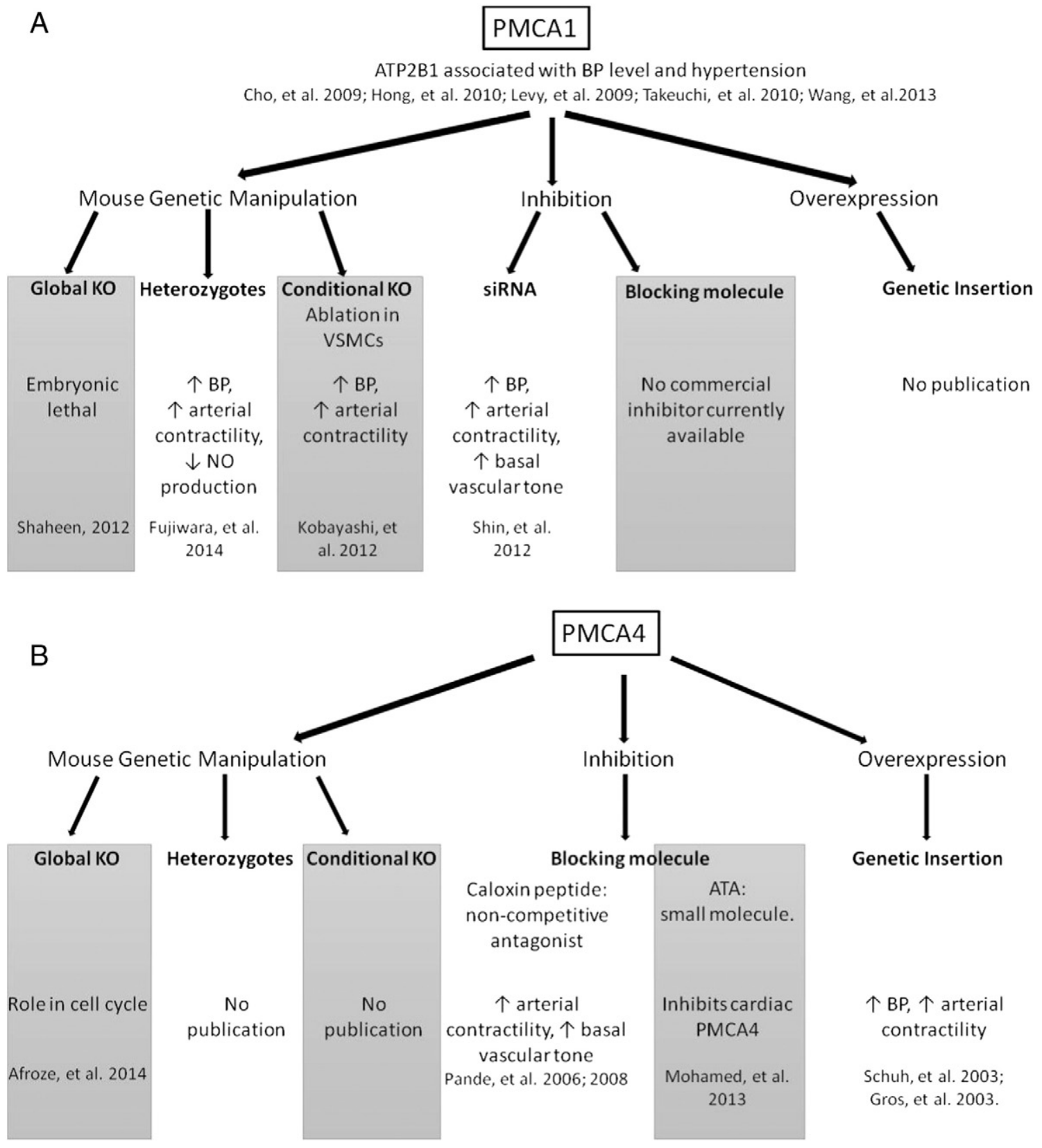

Fig. 3. Outline of experimental approaches assessing how PMCA1 (A.) and PMCA4 (B.) may have a role in vascular function and BP regulation. 
role(s) of PMCA1 and 4 in the development and progression of hypertension the clear association between PMCA and BP in humans coupled with experimental evidence supporting a direct role for PMCAs in modulation of arterial function and BP highlights PMCA as a potential new target for the treatment and management of hypertension. This warrants further investigation.

\section{Acknowledgments}

The authors declare that there are no conflicts of interest

The authors were supported by a programme grant from the Medical Research Council (MRC, UK) (G1002082) during the preparation of this manuscript. The funding body had no role in study design, collection, analysis and interpretation of data from work in our laboratory and had no influence on the submission of this manuscript.

This text has not been previously published, or is in consideration for publication, either wholly or in part.

\section{References}

Afroze, T., Yang, G., Khoshbin, A., Tanwir, M., Tabish, T., Momen, A., et al. (2014). Calcium efflux activity of plasma membrane Ca2 + ATPase-4 (PMCA4) mediates cell cycle progression in vascular smooth muscle cells. J Biol Chem 289, 7221-7231.

Afroze, T., Yang, L. L., Wang, C., Gros, R., Kalair, W., Hoque, A. N., et al. (2003). Calcineurinindependent regulation of plasma membrane $\mathrm{Ca} 2+$ ATPase- 4 in the vascular smooth muscle cell cycle. Am J Physiol Cell Physiol 285, C88-C95.

Agabiti-Rosei, E., \& Rizzoni, D. (2010). Regression of small resistance artery structural alterations in hypertension by appropriate antihypertensive treatment. Curr Hyperten Rep 12, 80-85.

Alli, A. A., Bao, H. F., Liu, B. C., Yu, L., Aldrugh, S., Montgomery, D. S., et al. (2015). Calmodulin and CaMKII modulate ENaC activity by regulating the association of MARCKS and the cytoskeleton with the apical membrane. Am J Physiol Renal Physiol 309, F456-F463.

Amberg, G. C., \& Navedo, M. F. (2013). Calcium dynamics in vascular smooth muscle. Microcirculation 20, 281-289.

Andre, G., Sandoval, J. E., Retailleau, K., Loufrani, L., Toumaniantz, G., Offermanns, S., et al. (2014). Smooth muscle specific Rac1 deficiency induces hypertension by preventing p116RIP3-dependent RhoA inhibition. J Am Heart Assoc 3, e000852.

Angus, J. A., Jennings, G. L., \& Sudhir, K. (1992). Enhanced contraction to noradrenaline serotonin and nerve stimulation but normal endothelium-derived relaxing factor response in skin small arteries in human primary hypertension. Clin Exp Pharmacol Physiol Suppl 19, 39-47.

Armesilla, A. L., Williams, J. C., Buch, M. H., Pickard, A Emerson, M., Cartwright, E. J., et al. (2004). Novel functional interaction between the plasma membrane Ca2+ pump 4b and the proapoptotic tumor suppressor Ras-associated factor 1 (RASSF1).J Biol Chem $279,31318-31328$

Badeer, H. S. (2001). Hemodynamics for medical students. Adv Physiol Educ 25, 44-52.

Baggott, R. R., Alfranca, A., Lopez-Maderuelo, D., Mohamed, T. M., Escolano, A., Oller, J. et al. (2014). Plasma membrane calcium ATPase isoform 4 inhibits vascular endothelial growth factor-mediated angiogenesis through interaction with calcineurin. Arterioscler Thromb Vasc Biol 34, 2310-2320.

Bakker, E. N., Buus, C. L., Spaan, J. A., Perree, J., Ganga, A., Rolf, T. M., et al. (2005). Smal artery remodeling depends on tissue-type transglutaminase. Circ Res 96, 119-126.

Bakker, E. N., Buus, C. L., VanBavel, E., \& Mulvany, M. J. (2004). Activation of resistance arteries with endothelin-1: From vasoconstriction to functional adaptation and remodeling. J Vasc Res 41, 174-182

Bakker, E. N., van Der Meulen, E. T., Spaan, J. A., \& VanBavel, E. (2000). Organoid culture of cannulated rat resistance arteries: Effect of serum factors on vasoactivity and remodeling. Am J Physiol Heart Circ Physiol 278, H1233-H1240.

Bakker, E. N., van der Meulen, E. T., van den Berg, B. M., Everts, V., Spaan, J. A., \& VanBavel, E. (2002). Inward remodeling follows chronic vasoconstriction in isolated resistance arteries. J Vasc Res 39, 12-20.

Bers, D. M. (2000). Calcium fluxes involved in control of cardiac myocyte contraction. Circ Res 87, 275-281.

Blaustein, M. P., \& Lederer, W. J. (1999). Sodium/calcium exchange: Its physiological implications. Physiol Rev 79, 763-854.

Bolotina, V. M., Najibi, S., Palacino, J. J., Pagano, P. J., \& Cohen, R. A. (1994). Nitric oxide directly activates calcium-dependent potassium channels in vascular smooth muscle. Nature 368, 850-853.

Brini, M. (2009). Plasma membrane $\mathrm{Ca}(2+)$-ATPase: From a housekeeping function to a versatile signaling role. Pflugers Arch 457, 657-664.

Buch, M. H., Pickard, A., Rodriguez, A., Gillies, S., Maass, A. H., Emerson, M., et al. (2005) The sarcolemmal calcium pump inhibits the calcineurin/nuclear factor of activated T-cell pathway via interaction with the calcineurin A catalytic subunit. J Biol Chem 280, 29479-29487.

Buchwalow, I. B., Podzuweit, T., Bocker, W., Samoilova, V. E., Thomas, S., Wellner, M., et al (2002). Vascular smooth muscle and nitric oxide synthase. FASEB J 16, 500-508.

Buus, N. H., Mathiassen, O. N., Fenger-Gron, M., Praestholm, M. N., Sihm, I., Thybo, N. K et al. (2013). Small artery structure during antihypertensive therapy is an independent predictor of cardiovascular events in essential hypertension. J Hypertens 31, 791-797.

Carafoli, E. (1991). The calcium pumping ATPase of the plasma membrane. Annu Rev Physiol 53, 531-547.

Carafoli, E., Santella, L., Branca, D., \& Brini, M. (2001). Generation, control, and processing of cellular calcium signals. Crit Rev Biochem Mol Biol 36, 107-260.

Cartwright, E. J., Mohamed, T., Oceandy, D., \& Neyses, L. (2011). Calcium signaling dysfunction in heart disease. Biofactors 37, 175-181.

Cartwright, E. J., Oceandy, D., \& Neyses, L. (2007). Plasma membrane calcium ATPase and its relationship to nitric oxide signaling in the heart. Ann N Y Acad Sci 1099, 247-253.

Chaudhary, J., Walia, M., Matharu, J., Escher, E., \& Grover, A. K. (2001). Caloxin: A novel plasma membrane Ca2 + pump inhibitor. Am J Physiol Cell Physiol 280, C1027-C1030.

Chen, J. B., Tao, R., Sun, H. Y., Tse, H. F., Lau, C. P., \& Li, G. R. (2010). Multiple Ca2+ signaling pathways regulate intracellular $\mathrm{Ca} 2+$ activity in human cardiac fibroblasts. $J$ Cell Physiol 223, 68-75.

Cho, Y. S., Go, M. J., Kim, Y. J., Heo, J. Y., Oh, J. H., Ban, H. J., et al. (2009). A large-scale genome-wide association study of Asian populations uncovers genetic factors influencing eight quantitative traits. Nat Genet 41, 527-534.

Chobanian, A. V., Bakris, G. L., Black, H. R., Cushman, W. C., Green, L. A., Izzo, J. L., Jr., et al. (2003). Seventh report of the Joint National Committee on Prevention, Detection, Evaluation, and Treatment of High Blood Pressure. Hypertension 42, 1206-1252.

Choi, S. H., Lee, B. H., Kim, H. J., Jung, S. W., Kim, H. S., Shin, H. C., et al. (2014). Ginseng gintonin activates the human cardiac delayed rectifier $\mathrm{K}+$ channel: Involvement of Ca2+/calmodulin binding sites. Mol Cells 37, 656-663.

Christensen, K. L., \& Mulvany, M. J. (2001). Location of resistance arteries. J Vasc Res 38, $1-12$.

Cura, C. I., Corradi, G. R., Rinaldi, D. E., \& Adamo, H. P. (2008). High sensibility to reactivation by acidic lipids of the recombinant human plasma membrane Ca2+-ATPase isoform 4xb purified from Saccharomyces cerevisiae. Biochim Biophys Acta 1778, 2757-2764.

Danaei, G., Finucane, M. M., Lu, Y., Singh, G. M., Cowan, M. J., Paciorek, C. J., et al. (2011). National, regional, and global trends in fasting plasma glucose and diabetes prevalence since 1980: Systematic analysis of health examination surveys and epidemiological studies with 370 country-years and 2.7 million participants. Lancet 378, 31-40.

De Ciuceis, C., Porteri, E., Rizzoni, D., Rizzardi, N., Paiardi, S., Boari, G. E., et al. (2007). Structural alterations of subcutaneous small-resistance arteries may predict major cardiovascular events in patients with hypertension. Am J Hypertens 20, 846-852.

Deng, A. Y. (2007). Genetic basis of polygenic hypertension. Hum Mol Genet 16(Spec No. 2), R195-R202.

Di Leva, F., Domi, T., Fedrizzi, L., Lim, D., \& Carafoli, E. (2008). The plasma membrane Ca2+ ATPase of animal cells: Structure, function and regulation. Arch Biochem Biophys 476, 65-74.

Duan, W Z Zhou, J., Li, W. Zhou, T. Chen, Q Yang F., et al (2013). Plasma membrane calcium ATPase 4b inhibits nitric oxide generation through calcium-induced dynamic interaction with neuronal nitric oxide synthase. Protein Cell 4, 286-298.

Earley, S., Reading, S., \& Brayden, J. E. (2007). Functional Significance of Transient Receptor Potential Channels in Vascular Function.

Eftekhari, A., Rahman, A., Schaebel, L. H., Chen, H., Rasmussen, C. V., Aalkjaer, C., et al. (2007). Chronic cystamine treatment inhibits small artery remodelling in rats. $J$ Vasc Res 44, 471-482.

Egan, B. M., Zhao, Y., \& Axon, R. N. (2010). US trends in prevalence, awareness, treatment, and control of hypertension, 1988-2008. JAMA 303, 2043-2050.

Ezzati, M., Lopez, A. D., Rodgers, A., Vander Hoorn, S., \& Murray, C. J. (2002). Selected major risk factors and global and regional burden of disease. Lancet 360, 1347-1360.

Feletou, M., \& Vanhoutte, P. M. (2009). EDHF: An update. Clin Sci (Lond) 117, 139-155.

Ferguson, J. F., Matthews, G. J., Townsend, R. R., Raj, D. S., Kanetsky, P. A., Budoff, M., et al. (2013). Candidate gene association study of coronary artery calcification in chronic kidney disease: Findings from the CRIC study (Chronic Renal Insufficiency Cohort). J Am Coll Cardiol 62, 789-798.

Fields, L. E., Burt, V. L., Cutler, J. A., Hughes, J., Roccella, E. J., \& Sorlie, P. (2004). The burden of adult hypertension in the United States 1999 to 2000: A rising tide. Hypertension 44, 398-404.

Filomatori, C. V., \& Rega, A. F. (2003). On the mechanism of activation of the plasma membrane Ca2+-ATPase by ATP and acidic phospholipids.J Biol Chem 278, 22265-22271.

Folkow, B. (2000). The debate on the 'amplifier hypothesis'-Some comments.J Hypertens $18,375-378$

Fontana, V., McDonough, C. W., Gong, Y., El Rouby, N. M., Sa, A. C., Taylor, K. D., et al. (2014). Large-scale gene-centric analysis identifies polymorphisms for resistant hypertension. J Am Heart Assoc 3, e001398.

Forstermann, U., Gath, I., Schwarz, P., Closs, E. I., \& Kleinert, H. (1995). Isoforms of nitric oxide synthase. Properties, cellular distribution and expressional control. Biochem Pharmacol 50, 1321-1332.

Fujii, K., Tominaga, M., Ohmori, S., Kobayashi, K., Koga, T., Takata, Y., et al. (1992). Decreased endothelium-dependent hyperpolarization to acetylcholine in smooth muscle of the mesenteric artery of spontaneously hypertensive rats. Circ Res 70, 660-669.

Fujiwara, A., Hirawa, N., Fujita, M., Kobayashi, Y., Okuyama, Y., Yatsu, K., et al. (2014). Impaired nitric oxide production and increased blood pressure in systemic heterozygous ATP2B1 null mice. J Hypertens 32, 1415-1423 (discussion 1423).

Furchgott, R. F., \& Zawadzki, J. V. (1980). The obligatory role of endothelial cells in the relaxation of arterial smooth muscle by acetylcholine. Nature 288, 373-376.

Ganesh, S. K., Tragante, V., Guo, W., Guo, Y., Lanktree, M. B., Smith, E. N., et al. (2013). Loci influencing blood pressure identified using a cardiovascular gene-centric array. Hum Mol Genet 22, 1663-1678.

Gollasch, M., Lohn, M., Furstenau, M., Nelson, M. T., Luft, F. C., \& Haller, H. (2000). Ca2+ channels, 'quantized' Ca2 + release, and differentiation of myocytes in the cardiovascular system. J Hypertens 18, 989-998. 
Gonzalez, R. G., Haxo, R. S., \& Schleich, T. (1980). Mechanism of action of polymeric aurintricarboxylic acid, a potent inhibitor of protein-nucleic acid interactions. Biochemistry 19, 4299-4303.

Gonzalez-Cobos, J. C., \& Trebak, M. (2010). TRPC channels in smooth muscle cells. Front Biosci (Landmark Ed) 15, 1023-1039.

Gros, R., Afroze, T., You, X. M., Kabir, G., Van Wert, R., Kalair, W., et al. (2003). Plasma membrane calcium ATPase overexpression in arterial smooth muscle increases vasomotor responsiveness and blood pressure. Circ Res 93, 614-621.

Hallick, R. B., Chelm, B. K., Gray, P. W., \& Orozco, E. M., Jr. (1977). Use of aurintricarboxylic acid as an inhibitor of nucleases during nucleic acid isolation. Nucleic Acids Res 4, 3055-3064.

Heagerty, A. M., Aalkjaer, C., Bund, S. J., Korsgaard, N., \& Mulvany, M. J. (1993). Small artery structure in hypertension. Dual processes of remodeling and growth. Hypertension 21, 391-397.

Heagerty, A. M., Heerkens, E. H., \& Izzard, A. S. (2010). Small artery structure and function in hypertension. J Cell Mol Med 14, 1037-1043.

Heerkens, E. H., Shaw, L., Ryding, A., Brooker, G., Mullins, J. J., Austin, C., et al. (2006). alphaV integrins are necessary for eutrophic inward remodeling of small arteries in hypertension. Hypertension 47, 281-287.

Heidenreich, P. A., Trogdon, J. G., Khavjou, O. A., Butler, J., Dracup, K., Ezekowitz, M. D., et al. (2011). Forecasting the future of cardiovascular disease in the United States: A policy statement from the American Heart Association. Circulation 123, 933-944.

Heo, S. G., Hwang, J. Y., Uhmn, S., Go, M. J., Oh, B., Lee, J. Y., et al. (2014). Male-specific genetic effect on hypertension and metabolic disorders. Hum Genet 133, 311-319.

Hill-Eubanks, D. C., Werner, M. E., Heppner, T. J., \& Nelson, M. T. (2011). Calcium signaling in smooth muscle. Cold Spring Harb Perspect Biol 3, a004549.

Hofmann, F., James, P., Vorherr, T., \& Carafoli, E. (1993). The C-terminal domain of the plasma membrane $\mathrm{Ca} 2+$ pump contains three high affinity $\mathrm{Ca} 2+$ binding sites. J Biol Chem 268, 10252-10259.

Holmes, M. E., Chaudhary, J., \& Grover, A. K. (2003). Mechanism of action of the novel plasma membrane $\mathrm{Ca}(2+)$-pump inhibitor caloxin. Cell Calcium 33, 241-245.

Holton, M., Mohamed, T. M., Oceandy, D., Wang, W., Lamas, S., Emerson, M., et al. (2010) Endothelial nitric oxide synthase activity is inhibited by the plasma membrane calcium ATPase in human endothelial cells. Cardiovasc Res 87, 440-448.

Hong, K. W., Go, M. J., Jin, H. S., Lim, J. E., Lee, J. Y., Han, B. G., et al. (2010). Genetic variations in ATP2B1, CSK, ARSG and CSMD1 loci are related to blood pressure and/or hypertension in two Korean cohorts. J Hum Hypertens 24, 367-372.

Ignarro, L. J. (2002). Nitric oxide as a unique signaling molecule in the vascular system: A historical overview. J Physiol Pharmacol 53, 503-514.

Iwamoto, T., Kita, S., Zhang, J., Blaustein, M. P., Arai, Y., Yoshida, S., et al. (2004). Saltsensitive hypertension is triggered by $\mathrm{Ca} 2+$ entry via $\mathrm{Na}+/ \mathrm{Ca} 2+$ exchanger type- 1 in vascular smooth muscle. Nat Med 10, 1193-1199.

Izzard, A. S., Bund, S. J., \& Heagerty, A. M. (1996). Myogenic tone in mesenteric arteries from spontaneously hypertensive rats. Am J Physiol 270, H1-H6.

Izzard, A. S., Heagerty, A. M., \& Leenen, F. H. (2002). The amplifier hypothesis: persisting dissent. J Hypertens 20, 375-377.

Izzard, A. S., Horton, S., Heerkens, E. H., Shaw, L., \& Heagerty, A. M. (2006). Middle cerebral artery structure and distensibility during developing and established phases of hypertension in the spontaneously hypertensive rat. J Hypertens $24,875-880$.

Izzard, A. S., Rizzoni, D., Agabiti-Rosei, E., \& Heagerty, A. M. (2005). Small artery structure and hypertension: Adaptive changes and target organ damage. J Hypertens 23, 247-250.

Jackson, W. F. (2000). Ion channels and vascular tone. Hypertension 35, 173-178.

James, P., Maeda, M., Fischer, R., Verma, A. K., Krebs, J., Penniston, J. T., et al. (1988). Identification and primary structure of a calmodulin binding domain of the $\mathrm{Ca} 2+$ pump of human erythrocytes. J Biol Chem 263, 2905-2910.

Johnson, T., Gaunt, T. R., Newhouse, S. J., Padmanabhan, S., Tomaszewski, M., Kumari, M., et al. (2011). Blood pressure loci identified with a gene-centric array. Am J Hum Genet $89,688-700$

Kaley, G., Koller, A., Rodenburg, J. M., Messina, E. J., \& Wolin, M. S. (1992). Regulation of arteriolar tone and responses via L-arginine pathway in skeletal muscle. Am J Physiol 262, H987-H992.

Kamishima, T., \& McCarron, J. G. (1998). Ca2+ removal mechanisms in rat cerebral resistance size arteries. Biophys J 75, 1767-1773.

Kang, K. T., Sullivan, J. C., Sasser, J. M., Imig, J. D., \& Pollock, J. S. (2007). Novel nitric oxide synthase-dependent mechanism of vasorelaxation in small arteries from hypertensive rats. Hypertension 49, 893-901.

Karaki, H., Ozaki, H., Hori, M., Mitsui-Saito, M., Amano, K., Harada, K., et al. (1997). Calcium movements, distribution, and functions in smooth muscle. Pharmacol Rev 49, 157-230.

Kearney, P. M., Whelton, M., Reynolds, K., Muntner, P., Whelton, P. K., \& He, J. (2005). Global burden of hypertension: Analysis of worldwide data. Lancet 365, 217-223.

Keeton, T. P., Burk, S. E., \& Shull, G. E. (1993). Alternative splicing of exons encoding the calmodulin-binding domains and $\mathrm{C}$ termini of plasma membrane $\mathrm{Ca}(2+)$-ATPase isoforms 1, 2, 3, and 4. J Biol Chem 268, 2740-2748.

Kelly, T. N., Takeuchi, F., Tabara, Y., Edwards, T. L., Kim, Y. J., Chen, P., et al. (2013). Genome-wide association study meta-analysis reveals transethnic replication of mean arterial and pulse pressure loci. Hypertension 62, 853-859.

Kenyon, K. A., Bushong, E. A., Mauer, A. S., Strehler, E. E., Weinberg, R. J., \& Burette, A. C. (2010). Cellular and subcellular localization of the neuron-specific plasma membrane calcium ATPase PMCA1a in the rat brain. J Comp Neurol 518, 3169-3183.

Kessler, F., Falchetto, R., Heim, R., Meili, R., Vorherr, T., Strehler, E. E., et al. (1992). Study of calmodulin binding to the alternatively spliced C-terminal domain of the plasma membrane Ca2+ pump. Biochemistry 31, 11785-11792.

Kim, D. I., Kang, M., Kim, S., Lee, J., Park, Y., Chang, I., et al. (2015). Molecular basis of the membrane interaction of the beta2e subunit of voltage-gated $\mathrm{Ca}(2+)$ channels. Biophys J 109, 922-935.
Kimura, K., Ito, M., Amano, M., Chihara, K., Fukata, Y., Nakafuku, M., et al. (1996). Regulation of myosin phosphatase by Rho and Rho-associated kinase (Rho-kinase). Science 273, 245-248.

Kobayashi, Y., Hirawa, N., Tabara, Y., Muraoka, H., Fujita, M., Miyazaki, N., et al. (2012) Mice lacking hypertension candidate gene ATP2B1 in vascular smooth muscle cells show significant blood pressure elevation. Hypertension 59, 854-860.

Korner, P. I., Angus, J. A., \& Wright, C. E. (2000). Structure and the resistance amplifier in hypertension: Reply to the dissenters. J Hypertens 18, 235-239.

Korsgaard, N., Aalkjaer, C., Heagerty, A. M., Izzard, A. S., \& Mulvany, M. J. (1993). Histology of subcutaneous small arteries from patients with essential hypertension. Hypertension 22, 523-526.

Kotchen, T. A., Kotchen, J. M., Grim, C. E., George, V., Kaldunski, M. L., Cowley, A. W., et al. (2000). Genetic determinants of hypertension: Identification of candidate phenotypes. Hypertension 36, 7-13.

Kozel, P. J., Friedman, R. A., Erway, L. C., Yamoah, E. N., Liu, L. H., Riddle, T., et al. (1998) Balance and hearing deficits in mice with a null mutation in the gene encoding plasma membrane Ca2+-ATPase isoform 2. J Biol Chem 273, 18693-18696.

Kudryavtseva, O., Aalkjaer, C., \& Matchkov, V. V. (2013). Vascular smooth muscle cell phenotype is defined by Ca2+-dependent transcription factors. FEBS J 280, 5488-5499.

Kupper, N., Willemsen, G., Riese, H., Posthuma, D., Boomsma, D. I., \& de Geus, E. J. (2005) Heritability of daytime ambulatory blood pressure in an extended twin design. Hypertension 45, 80-85.

Kur, J., Bankhead, P., Scholfield, C. N., Curtis, T. M., \& McGeown, J. G. (2013). Ca(2+) sparks promote myogenic tone in retinal arterioles. Br J Pharmacol 168, 1675-1686.

Lalli, J., Harrer, J. M., Luo, W., Kranias, E. G., \& Paul, R. J. (1997). Targeted ablation of the phospholamban gene is associated with a marked decrease in sensitivity in aortic smooth muscle. Circ Res 80, 506-513.

Laurant, P., Touyz, R. M., \& Schiffrin, E. L. (1997). Effect of pressurization on mechanical properties of mesenteric small arteries from spontaneously hypertensive rats. J Vasc Res 34, 117-125.

Law, M. R., Morris, J. K., \& Wald, N. J. (2009). Use of blood pressure lowering drugs in the prevention of cardiovascular disease: Meta-analysis of 147 randomised trials in the context of expectations from prospective epidemiological studies. BMJ 338, b1665.

Lawes, C. M., Vander Hoorn, S., \& Rodgers, A. (2008). Global burden of blood-pressurerelated disease, 2001. Lancet 371, 1513-1518.

Lee, M., Guo, J. P., Schwab, C., McGeer, E. G., \& McGeer, P. L. (2012). Selective inhibition of the membrane attack complex of complement by low molecular weight components of the aurin tricarboxylic acid synthetic complex. Neurobiol Aging 33, 2237-2246.

Levy, D., Ehret, G. B., Rice, K., Verwoert, G. C., Launer, L. J., Dehghan, A., et al. (2009) Genome-wide association study of blood pressure and hypertension. Nat Genet 41, 677-687.

Lewington, S., Clarke, R., Qizilbash, N., Peto, R., \& Collins, R. (2002). Age-specific relevance of usual blood pressure to vascular mortality: A meta-analysis of individual data for one million adults in 61 prospective studies. Lancet 360, 1903-1913.

Li, M., Allen, A., \& Smith, T. J. (2007). High throughput screening reveals several new classes of glutamate dehydrogenase inhibitors. Biochemistry 46, 15089-15102.

Li, J., \& Bukoski, R. D. (1993). Endothelium-dependent relaxation of hypertensive resistance arteries is not impaired under all conditions. Circ Res 72, 290-296.

Li, H., Wallerath, T., \& Forstermann, U. (2002). Physiological mechanisms regulating the expression of endothelial-type NO synthase. Nitric Oxide 7, 132-147.

Lim, S. S., Vos, T., Flaxman, A. D., Danaei, G., Shibuya, K., Adair-Rohani, H., et al. (2012). A comparative risk assessment of burden of disease and injury attributable to 67 risk factors and risk factor clusters in 21 regions, 1990-2010: A systematic analysis for the Global Burden of Disease Study 2010. Lancet 380, 2224-2260.

Lipo, E., Cashman, S. M., \& Kumar-Singh, R. (2013). Aurintricarboxylic acid inhibits complement activation, membrane attack complex, and choroidal neovascularization in a model of macular degeneration. Invest Ophthalmol Vis Sci 54(10), 7107-7114.

Liu, L., Ishida, Y., Okunade, G., Shull, G. E., \& Paul, R. J. (2006). Role of plasma membrane $\mathrm{Ca} 2+-$ ATPase in contraction-relaxation processes of the bladder: Evidence from PMCA gene-ablated mice. Am J Physiol Cell Physiol 290, C1239-C1247.

Lloyd-Jones, D. M., Evans, J. C., \& Levy, D. (2005). Hypertension in adults across the age spectrum: Current outcomes and control in the community. JAMA 294, 466-472.

Lopreiato, R., Giacomello, M., \& Carafoli, E. (2014). The plasma membrane calcium pump: New ways to look at an old enzyme. J Biol Chem 289, 10261-10268.

Luscher, T. F. (1994). The endothelium in hypertension: bystander, target or mediator? J Hypertens Suppl 12, S105-S116.

Mackiewicz, U., Maczewski, M., Konior, A., Tellez, J. O., Nowis, D., Dobrzynski, H., et al. (2009). Sarcolemmal Ca2+-ATPase ability to transport Ca2+ gradually diminishes after myocardial infarction in the rat. Cardiovasc Res 81, 546-554.

Mancia, G., Fagard, R., Narkiewicz, K., Redon, J., Zanchetti, A., Bohm, M., et al. (2013). 2013 ESH/ESC Guidelines for the management of arterial hypertension: The Task Force for the management of arterial hypertension of the European Society of Hypertension (ESH) and of the European Society of Cardiology (ESC). J Hypertens 31, 1281-1357.

Martinez-Lemus, L. A., Hill, M. A., \& Meininger, G. A. (2009). The plastic nature of the vascular wall: A continuum of remodeling events contributing to control of arteriolar diameter and structure. Physiology (Bethesda) 24, 45-57.

Mathiassen, O. N., Buus, N. H., Larsen, M. L., Mulvany, M. J., \& Christensen, K. L. (2007a), Small artery structure adapts to vasodilatation rather than to blood pressure during antihypertensive treatment. J Hypertens 25, 1027-1034.

Mathiassen, O. N., Buus, N. H., Sihm, I., Thybo, N. K., Morn, B., Schroeder, A. P., et al. (2007b). Small artery structure is an independent predictor of cardiovascular events in essential hypertension. J Hypertens 25, 1021-1026.

Matthew, A., Shmygol, A., \& Wray, S. (2004). Ca2+ entry, efflux and release in smooth muscle. Biol Res 37, 617-624.

McCarron, J. G., Chalmers, S., Bradley, K. N., MacMillan, D., \& Muir, T. C. (2006). Ca2+ microdomains in smooth muscle. Cell Calcium 40, 461-493. 
McCarthy, N. S., Vangjeli, C., Cavalleri, G. L., Delanty, N., Shianna, K. V., Surendran, P., et al. (2014). Two further blood pressure loci identified in ion channel genes with a genecentric approach. Circ Cardiovasc Genet 7, 873-879.

Messerli, F. H., Williams, B., \& Ritz, E. (2007). Essential hypertension. Lancet 370, 591-603.

Miall, W. E., \& Oldham, P. D. (1963). The hereditary factor in arterial blood-pressure. Br Med J 1, 75-80.

Miyaki, K., Htun, N. C., Song, Y., Ikeda, S., Muramatsu, M., \& Shimbo, T. (2012). The combined impact of 12 common variants on hypertension in Japanese men, considering GWAS results. J Hum Hypertens 26, 430-436.

Mohamed, T. M., Abou-Leisa, R., Baudoin, F., Stafford, N., Neyses, L., Cartwright, E. J., et al. (2013). Development and characterization of a novel fluorescent indicator protein PMCA4-GCaMP2 in cardiomyocytes. J Mol Cell Cardiol 63, 57-68.

Mohamed, T. M., Oceandy, D., Zi, M., Prehar, S., Alatwi, N., Wang, Y., et al. (2011). Plasma membrane calcium pump (PMCA4)-neuronal nitric-oxide synthase complex regulates cardiac contractility through modulation of a compartmentalized cyclic nucleotide microdomain. J Biol Chem 286, 41520-41529.

Mombouli, J. V., \& Vanhoutte, P. M. (1999). Endothelial dysfunction: From physiology to therapy. J Mol Cell Cardiol 31, 61-74.

Momen, A., Afroze, T., Sadi, A. M., Khoshbin, A., Zhang, H., Choi, J., et al. (2014). Enhanced proliferation and altered calcium handling in RGS2-deficient vascular smooth muscle cells. J Recept Signal Transduct Res 34, 476-483.

Mongeau, J. G. (1989). Hypertension in children. Patterns of inheritance and implications for screening and management. Drugs 38, 175-179.

Mori, M. X., Itsuki, K., Hase, H., Sawamura, S., Kurokawa, T., Mori, Y., et al. (2015). Dynamics of receptor-operated $\mathrm{Ca}(2+)$ currents through TRPC channels controlled via the PI(4,5)P2-PLC signaling pathway. Front Pharmacol 6, 22.

Morisky, D. E., Ang, A., Krousel-Wood, M., \& Ward, H. J. (2008). Predictive validity of a medication adherence measure in an outpatient setting. J Clin Hypertens (Greenwich) 10, 348-354.

Muiesan, M. L., Salvetti, M., Rizzoni, D., Paini, A., Agabiti-Rosei, C., Aggiusti, C., et al. (2013) Resistant hypertension and target organ damage. Hypertens Res 36, 485-491.

Mulvany, M. J. (2012). Small artery remodelling in hypertension. Basic Clin Pharmacol Toxicol 110, 49-55.

Mulvany, M. J., \& Aalkjaer, C. (1990). Structure and function of small arteries. Physiol Rev 70, 921-961.

Nelson, M. T., Cheng, H., Rubart, M., Santana, L. F., Bonev, A. D., Knot, H. J., et al. (1995) Relaxation of arterial smooth muscle by calcium sparks. Science 270, 633-637.

NICE (2011). Hypertension: Clinical Management of Primary Hypertension in Adults. Cardiovascular Conditions (Vol. 2014).

Oceandy, D., Cartwright, E. J., Emerson, M., Prehar, S., Baudoin, F. M., Zi, M., et al. (2007). Neuronal nitric oxide synthase signaling in the heart is regulated by the sarcolemmal calcium pump 4b. Circulation 115, 483-492.

Okada, N., \& Koizumi, S. (1995). A neuroprotective compound, aurin tricarboxylic acid, stimulates the tyrosine phosphorylation cascade in PC12 cells. J Biol Chem 270, 16464-16469.

Okunade, G. W., Miller, M. L., Pyne, G. J., Sutliff, R. L., O'Connor, K. T., Neumann, J. C., et al. (2004). Targeted ablation of plasma membrane Ca2+-ATPase (PMCA) 1 and 4 indicates a major housekeeping function for PMCA1 and a critical role in hyperactivated sperm motility and male fertility for PMCA4. J Biol Chem 279, 33742-33750.

Oloizia, B., \& Paul, R. J. (2008). Ca2 + clearance and contractility in vascular smooth muscle: Evidence from gene-altered murine models. J Mol Cell Cardiol 45, 347-362.

O'Shaughnessy, K. M. (2001). The genetics of essential hypertension. Br J Clin Pharmacol $51,5-11$.

Pande, J., Mallhi, K. K., Sawh, A., Szewczyk, M. M., Simpson, F., \& Grover, A. K. (2006). Aortic smooth muscle and endothelial plasma membrane Ca2+ pump isoforms are inhibited differently by the extracellular inhibitor caloxin 1b1. Am J Physiol Cell Physiol 290. C1341-C1349.

Pande, J., Szewczyk, M. M., Kuszczak, I., Grover, S., Escher, E., \& Grover, A. K. (2008). Functional effects of caloxin 1c2, a novel engineered selective inhibitor of plasma membrane $\mathrm{Ca}(2+)$-pump isoform 4, on coronary artery. J Cell Mol Med 12, 1049-1060.

Parekh, A. B., \& Putney, J. W., Jr. (2005). Store-operated calcium channels. Physiol Rev 85, 757-810

Pesic, A., Madden, J. A., Pesic, M., \& Rusch, N. J. (2004). High blood pressure upregulates arterial L-type Ca2 + channels: Is membrane depolarization the signal? Circ Res 94 e97-e104.

Pfeifer, A., Klatt, P., Massberg, S., Ny, L., Sausbier, M., Hirneiss, C., et al. (1998). Defective smooth muscle regulation in cGMP kinase I-deficient mice. EMBO J 17 . 3045-3051.

Pickering, G. (1972). Hypertension. Definitions, natural histories and consequences. Am J Med 52, 570-583.

Quednau, B. D., Nicoll, D. A., \& Philipson, K. D. (1997). Tissue specificity and alternative splicing of the $\mathrm{Na}+/ \mathrm{Ca} 2+$ exchanger isoforms NCX1, NCX2, and NCX3 in rat. Am J Physiol 272, C1250-C1261

Renna, N. F., de Las Heras, N., \& Miatello, R. M. (2013). Pathophysiology of vascular remodeling in hypertension. Int J Hypertens 2013, 808353.

Rizzoni, D., Aalkjaer, C., De Ciuceis, C., Porteri, E., Rossini, C., Rosei, C. A., et al. (2011). How to assess microvascular structure in humans. High Blood Press Cardiovasc Prev 18 $169-177$.

Rizzoni, D., \& Agabiti-Rosei, E. (2012). Structural abnormalities of small resistance arteries in essential hypertension. Intern Emerg Med 7, 205-212.

Rizzoni, D., Porteri, E., Boari, G. E., De Ciuceis, C., Sleiman, I., Muiesan, M. L., et al. (2003). Prognostic significance of small-artery structure in hypertension. Circulation 108 $2230-2235$

Rizzoni, D., Porteri, E., Castellano, M., Bettoni, G., Muiesan, M. L., Muiesan, P., et al. (1996) Vascular hypertrophy and remodeling in secondary hypertension. Hypertension 28 785-790.
Rizzoni, D., Porteri, E., Castellano, M., Bettoni, G., Muiesan, M. L., Tiberio, G., et al. (1998). Endothelial dysfunction in hypertension is independent from the etiology and from vascular structure. Hypertension 31, 335-341.

Rizzoni, D., Porteri, E., De Ciuceis, C., Boari, G. E., Zani, F., Miclini, M., et al. (2006). Lack of prognostic role of endothelial dysfunction in subcutaneous small resistance arteries of hypertensive patients. J Hypertens 24, 867-873.

Roger, V. L., Go, A. S., Lloyd-Jones, D. M., Benjamin, E. J., Berry, J. D., Borden, W. B., et al. (2012). Heart disease and stroke statistics-2012 update: A report from the American Heart Association. Circulation 125, e2-e220.

Sakhuja, A., Textor, S. C., \& Taler, S. J. (2015). Uncontrolled hypertension by the 2014 evidence-based guideline: Results from NHANES 2011-2012. J Hypertens 33, 644-651 (discussion 652).

Sasamura, S., Furukawa, K., Shiratori, M., Motomura, S., \& Ohizumi, Y. (2002). Antisenseinhibition of plasma membrane Ca2 + pump induces apoptosis in vascular smooth muscle cells. Jpn J Pharmacol 90, 164-172.

Schiffrin, E. L. (2004). Remodeling of resistance arteries in essential hypertension and effects of antihypertensive treatment. Am J Hypertens 17, 1192-1200.

Schuh, K., Cartwright, E. J., Jankevics, E., Bundschu, K., Liebermann, J., Williams, J. C., et al. (2004). Plasma membrane Ca2 + ATPase 4 is required for sperm motility and male fertility. J Biol Chem 279, 28220-28226

Schuh, K., Quaschning, T., Knauer, S., Hu, K., Kocak, S., Roethlein, N., et al. (2003). Regulation of vascular tone in animals overexpressing the sarcolemmal calcium pump. J Biol Chem 278, 41246-41252.

Schuh, K., Uldrijan, S., Telkamp, M., Rothlein, N., \& Neyses, L. (2001). The plasmamembrane calmodulin-dependent calcium pump: A major regulator of nitric oxide synthase I. J Cell Biol 155, 201-205.

Schwarz, P. M., Kleinert, H., \& Forstermann, U. (1999). Potential functional significance of brain-type and muscle-type nitric oxide synthase I expressed in adventitia and media of rat aorta. Arterioscler Thromb Vasc Biol 19, 2584-2590.

Shaheen, M. (2012). Determining the Role of Plasma Membrane Ca2 + ATPase 1 in Heart Failure. Manchester: The University of Manchester

Shin, Y. B., Lim, J. E., Ji, S. M., Lee, H. J., Park, S. Y., Hong, K. W., et al. (2013). Silencing of Atp2b1 increases blood pressure through vasoconstriction. J Hypertens 31, 1575-1583.

Somlyo, A. P., \& Somlyo, A. V. (1994). Signal transduction and regulation in smooth muscle. Nature 372, 231-236.

Sonkusare, S., Palade, P. T., Marsh, J. D., Telemaque, S., Pesic, A., \& Rusch, N. J. (2006). Vascular calcium channels and high blood pressure: Pathophysiology and therapeutic implications. Vascul Pharmacol 44, 131-142.

Sriram, K., Intaglietta, M., \& Tartakovsky, D. M. (2014). Non-Newtonian flow of blood in arterioles: Consequences for wall shear stress measurements. Microcirculation 21(7), 628-639.

Staiculescu, M. C., Galinanes, E. L., Zhao, G., Ulloa, U., Jin, M., Beig, M. I., et al. (2013). Prolonged vasoconstriction of resistance arteries involves vascular smooth muscle actin polymerization leading to inward remodelling. Cardiovasc Res 98, 428-436.

Stekiel, W. J., Contney, S. J., \& Lombard, J. H. (1986). Small vessel membrane potential, sympathetic input, and electrogenic pump rate in SHR. Am J Physiol 250, C547-C556.

Street, V. A., McKee-Johnson, J. W., Fonseca, R. C., Tempel, B. L., \& Noben-Trauth, K. (1998). Mutations in a plasma membrane Ca2+-ATPase gene cause deafness in deafwaddler mice. Nat Genet 19, 390-394.

Strehler, E. E. (2015). Plasma membrane calcium ATPases: From generic $\mathrm{Ca}(2+)$ sump pumps to versatile systems for fine-tuning cellular $\mathrm{Ca}(2$.). Biochem Biophys Res Commun 460, 26-33.

Szewczyk, M. M., Davis, K. A., Samson, S. E., Simpson, F., Rangachari, P. K., \& Grover, A. K. (2007). Ca2+-pumps and $\mathrm{Na} 2+-\mathrm{Ca} 2+$-exchangers in coronary artery endothelium versus smooth muscle. J Cell Mol Med 11, 129-138.

Szewczyk, M. M., Pande, J., Akolkar, G., \& Grover, A. K. (2010). Caloxin 1b3: A novel plasma membrane $\mathrm{Ca}(2+)$-pump isoform 1 selective inhibitor that increases cytosolic $\mathrm{Ca}(2+)$ in endothelial cells. Cell Calcium 48, 352-357.

Szewczyk, M. M., Pande, J., \& Grover, A. K. (2008). Caloxins: A novel class of selective plasma membrane $\mathrm{Ca} 2+$ pump inhibitors obtained using biotechnology. Pflugers Arch 456, 255-266.

Tabara, Y., Kohara, K., Kita, Y., Hirawa, N., Katsuya, T., Ohkubo, T., et al. (2010). Common variants in the ATP2B1 gene are associated with susceptibility to hypertension: The Japanese Millennium Genome Project. Hypertension 56, 973-980.

Taddei, S., Virdis, A., Mattei, P., Ghiadoni, L., Fasolo, C. B., Sudano, I., et al. (1997). Hypertension causes premature aging of endothelial function in humans. Hypertension 29, 736-743.

Taguchi, K., Matsumoto, T., \& Kobayashi, T. (2015). G-protein-coupled receptor kinase 2 and endothelial dysfunction: Molecular insights and pathophysiological mechanisms. J Smooth Muscle Res 51, 37-49.

Takeuchi, F., Isono, M., Katsuya, T., Yamamoto, K., Yokota, M., Sugiyama, T., et al. (2010). Blood pressure and hypertension are associated with 7 loci in the Japanese population. Circulation 121, 2302-2309.

Takeya, K., Wang, X., Sutherland, C., Kathol, I., Loutzenhiser, K., Loutzenhiser, R. D., et al. (2014). Involvement of myosin regulatory light chain diphosphorylation in sustained vasoconstriction under pathophysiological conditions. J Smooth Muscle Res 50, 18-28.

Tan, G. S., Chiu, C. H., Garchow, B. G., Metzler, D., Diamond, S. L., \& Kiriakidou, M. (2012). Small molecule inhibition of RISC loading. ACS Chem Biol 7, 403-410.

Tomaszewski, M., White, C., Patel, P., Masca, N., Damani, R., Hepworth, J., et al. (2014). High rates of non-adherence to antihypertensive treatment revealed by highperformance liquid chromatography-tandem mass spectrometry (HP LC-MS/MS) urine analysis. Heart 100, 855-861.

Tragante, V., Barnes, M. R., Ganesh, S. K., Lanktree, M. B., Guo, W., Franceschini, N., et al. (2014). Gene-centric meta-analysis in 87,736 individuals of European ancestry identifies multiple blood-pressure-related loci. Am J Hum Genet 94, 349-360. 
Tumelty, J., Scholfield, N., Stewart, M., Curtis, T., \& McGeown, G. (2007). Ca2+-sparks constitute elementary building blocks for global $\mathrm{Ca} 2+$-signals in myocytes of retinal arterioles. Cell Calcium 41, 451-466.

Uehata, M., Ishizaki, T., Satoh, H., Ono, T., Kawahara, T., Morishita, T., et al. (1997). Calcium sensitization of smooth muscle mediated by a Rho-associated protein kinase in hypertension. Nature 389, 990-994.

Urakami-Harasawa, L., Shimokawa, H., Nakashima, M., Egashira, K., \& Takeshita, A. (1997). Importance of endothelium-derived hyperpolarizing factor in human arteries. J Clin Invest 100, 2793-2799.

Vanhoutte, P. M., Feletou, M., \& Taddei, S. (2005). Endothelium-dependent contractions in hypertension. Br J Pharmacol 144, 449-458.

Vega, J., \& Bisognano, J. D. (2014). The prevalence, incidence, prognosis, and associated conditions of resistant hypertension. Semin Nephrol 34, 247-256.

Vongpatanasin, W. (2014). Resistant hypertension: a review of diagnosis and management. JAMA 311, 2216-2224.

Waldman, S. A., \& Murad, F. (1987). Cyclic GMP synthesis and function. Pharmacol Rev 39, 163-196.

Wang, Y., Zhang, Y., Li, Y., Zhou, X., Wang, X., Gao, P., et al. (2013). Common variants in the ATP2B1 gene are associated with hypertension and arterial stiffness in Chinese population. Mol Biol Rep 40, 1867-1873.

Webb, G. D., Lim, L. H., Oh, V. M., El Oakley, R., Lee, C. N., Wong, P. S., et al. (2006). Expression of neuronal nitric oxide synthase in the internal thoracic artery and saphenous vein. J Thorac Cardiovasc Surg 132, 1131-1136.

Whelton, P. K. (1994). Epidemiology of hypertension. Lancet 344, 101-106.

Whitworth, J. A. (2003). 2003 World Health Organization (WHO)/International Society of Hypertension (ISH) statement on management of hypertension. J Hypertens 21, 1983-1992.

WHO (2013). A Global Brief on Hypertension. Geneva: World Health Organisation, 39.

WHO (2014). 10 Facts on Ageing and the Life Course. (In (Vol. 2015, pp. Ageing in relation to population health). Geneva).
Williams, J. C., Armesilla, A. L., Mohamed, T. M., Hagarty, C. L., McIntyre, F. H., Schomburg S., et al. (2006). The sarcolemmal calcium pump, alpha-1 syntrophin, and neuronal nitric-oxide synthase are parts of a macromolecular protein complex. J Biol Chem 281, 23341-23348.

Wilson, P. W. (1994). Established risk factors and coronary artery disease: The Framingham Study. Am J Hypertens 7, 7S-12S.

Wright, C. E., \& Angus, J. A. (1999). Enhanced total peripheral vascular responsiveness in hypertension accords with the amplifier hypothesis. J Hypertens 17, 1687-1696.

Wu, X., Chang, B., Blair, N. S., Sargent, M., York, A. J., Robbins, J., et al. (2009). Plasma membrane Ca2+-ATPase isoform 4 antagonizes cardiac hypertrophy in association with calcineurin inhibition in rodents. J Clin Invest 119, 976-985.

Xi, B., Tang, W., \& Wang, Q. (2012). Polymorphism near the ATP2B1 gene is associated with hypertension risk in East Asians: a meta-analysis involving 15909 cases and 18529 controls. Blood Press 21, 134-138.

Yusuf, S., Reddy, S., Ounpuu, S., \& Anand, S. (2001). Global burden of cardiovascular diseases: part I: general considerations, the epidemiologic transition, risk factors, and impact of urbanization. Circulation 104, 2746-2753.

Zacchigna, L., Vecchione, C., Notte, A., Cordenonsi, M., Dupont, S., Maretto, S., et al. (2006) Emilin1 links TGF-beta maturation to blood pressure homeostasis. Cell 124, 929-942.

Zhang, J., Ren, C., Chen, L., Navedo, M. F., Antos, L. K., Kinsey, S. P., et al. (2010). Knockout of $\mathrm{Na}+/ \mathrm{Ca} 2+$ exchanger in smooth muscle attenuates vasoconstriction and L-type $\mathrm{Ca} 2+$ channel current and lowers blood pressure. Am J Physiol Heart Circ Physiol 298, H1472-H1483.

Zhao, D., Zhang, J., Blaustein, M. P., \& Navar, L. G. (2011). Attenuated renal vascular responses to acute angiotensin II infusion in smooth muscle-specific $\mathrm{Na}+/ \mathrm{Ca} 2+$ exchanger knockout mice. Am J Physiol Renal Physiol 301, F574-F579.

Zuk, O., Hechter, E., Sunyaev, S. R., \& Lander, E. S. (2012). The mystery of missing heritability: Genetic interactions create phantom heritability. Proc Natl Acad Sci U S A 109 1193-1198. 


\section{Related Articles}

\section{http://fulltext.study/journal/2219}

\section{fullText.study}

E Categorized Journals

Thousands of scientific journals broken down into different categories to simplify your search

\section{Full-Text Access}

The full-text version of all the articles are available for you to purchase at the lowest price

Free Downloadable Articles

In each journal some of the articles are available to download for free

Free PDF Preview

A preview of the first 2 pages of each article is available for you to download for free

\section{http://FullText.Study}

